\title{
Fusing Carbocycles of Inequivalent Ring Size to a Bis(imino)pyridine-Iron Ethylene Polymerization Catalyst: Distinctive Effects on Activity, PE Molecular Weight, and Dispersity
}

\author{
Zheng Wang $\mathbb{D}^{\mathbb{1}}{ }^{1,2}$ Gregory A. Solan $\mathbb{D}^{1,3}$ Yanping Ma, ${ }^{1,2}$ Qingbin Liu, ${ }^{4}$ Tongling Liang, $^{1}$ \\ and Wen-Hua Sun $(\mathbb{D})^{1,2,5}$ \\ ${ }^{1}$ Key Laboratory of Engineering Plastics and Beijing National Laboratory for Molecular Science, Institute of Chemistry, \\ Chinese Academy of Sciences, Beijing 100190, China \\ ${ }^{2}$ CAS Research/Education Center for Excellence in Molecular Sciences, University of Chinese Academy of Sciences, \\ Beijing 100049, China \\ ${ }^{3}$ Department of Chemistry, University of Leicester, University Road, Leicester LE1 7RH, UK \\ ${ }^{4}$ College of Chemistry and Material Science, Hebei Normal University, Shijiazhuang 050024, China \\ ${ }^{5}$ State Key Laboratory for Oxo Synthesis and Selective Oxidation, Lanzhou Institute of Chemical Physics, Chinese Academy \\ of Sciences, Lanzhou 730000, China
}

Correspondence should be addressed to Gregory A. Solan; gas8@leicester.ac.uk, Qingbin Liu; qbinliu@sina.com, and Wen-Hua Sun; whsun@iccas.ac.cn

Received 24 April 2019; Accepted 5 August 2019; Published 16 October 2019

Copyright () 2019 Zheng Wang et al. Exclusive Licensee Science and Technology Review Publishing House. Distributed under a Creative Commons Attribution License (CC BY 4.0).

The 4,6-bis(arylimino)-1,2,3,7,8,9,10-heptahydrocyclohepta[b] quinoline-iron(II) chlorides (aryl=2,6- $\mathrm{Me}_{2} \mathrm{C}_{6} \mathrm{H}_{3} \mathbf{F e l} ; 2,6-\mathrm{Et}_{2} \mathrm{C}_{6} \mathrm{H}_{3}$ Fe2; 2,6-i- $\mathrm{Pr}_{2} \mathrm{C}_{6} \mathrm{H}_{3}$ Fe3; 2,4,6- $\mathrm{Me}_{3} \mathrm{C}_{6} \mathrm{H}_{2}$ Fe4; and 2,6- $\mathrm{Et}_{2}-4-\mathrm{Me}_{2} \mathrm{C}_{6} \mathrm{H}_{2}$ Fe5) have been prepared in good yield by a straightforward one-pot reaction of 2,3,7,8,9,10-hexahydro- $1 \mathrm{H}$-cyclohepta[b]quinoline-4,6-dione, $\mathrm{FeCl}_{2} \cdot 4 \mathrm{H}_{2} \mathrm{O}$, and the appropriate aniline in acetic acid. All ferrous complexes have been characterized by elemental analysis and FT-IR spectroscopy. In addition, the structure of Fe3 has been determined by single crystal X-ray diffraction, which showed the iron center to adopt a distorted square pyramidal geometry with the saturated sections of the fused six- and sevenmembered carbocycles to be cis-configured. In combination with either MAO or MMAO, Fe1-Fe5 exhibited exceptionally high activities for ethylene polymerization (up to $15.86 \times 10^{6} \mathrm{~g}(\mathrm{PE}) \mathrm{mol}^{-1}(\mathrm{Fe}) \mathrm{h}^{-1}$ at $40^{\circ} \mathrm{C}(\mathrm{MMAO})$ and $9.60 \times 10^{6} \mathrm{~g}(\mathrm{PE}) \mathrm{mol}^{-1}$ $(\mathrm{Fe}) \mathrm{h}^{-1}$ at $60^{\circ} \mathrm{C}(\mathrm{MAO})$ ) and produced highly linear polyethylene (HLPE, $T_{\mathrm{m}} \geq 128^{\circ} \mathrm{C}$ ) with a wide range in molecular weights; in general, the MMAO-promoted polymerizations were more active. Irrespective of the cocatalyst employed, the 2,6-Me $2^{-}$ substituted $\mathrm{Fe} 1$ and $\mathrm{Fe} 4$ proved the most active while the more sterically hindered 2,6-i-Pr $\mathrm{P}_{2} \mathrm{Fe} 3$ the least but afforded the highest molecular weight polyethylene $\left(M_{\mathrm{w}}\right.$ : 65.6-72.6 $\left.\mathrm{kg} \mathrm{mol}^{-1}\right)$. Multinuclear NMR spectroscopic analysis of the polymer formed using $\mathrm{Fe} 4 / \mathrm{MMAO}$ at $40^{\circ} \mathrm{C}$ showed a preference for fully saturated chain ends with a broad bimodal distribution a feature of the GPC trace $\left(M_{\mathrm{w}} / M_{\mathrm{n}}=13.4\right)$. By contrast, using Fe4/MAO at $60^{\circ} \mathrm{C}$ a vinyl-terminated polymer of lower molecular weight $\left(M_{\mathrm{w}}=14.2 \mathrm{~kg} \mathrm{~mol}^{-1}\right)$ was identified that exhibited a unimodal distribution $\left(M_{\mathrm{w}} / M_{\mathrm{n}}=3.8\right)$. Moreover, the amount of aluminoxane cocatalyst employed, temperature, and run time were also found to be influential on the modality of the polymer. 


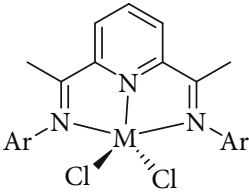

$\mathrm{A}(\mathrm{Co}, \mathrm{Fe})$

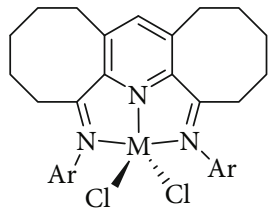

$\mathbf{D}(\mathrm{Co}, \mathrm{Fe})$

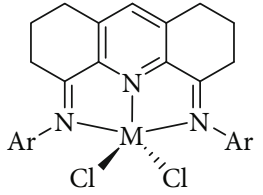

B $(\mathrm{Co}, \mathrm{Fe})$

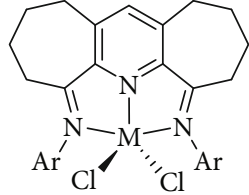

$\mathrm{C}(\mathrm{Co}, \mathrm{Fe})$

Figure 1: Bis(imino)pyridine-metal(II) chlorides $\mathbf{A}$ and their doubly fused derivatives $\mathbf{B}-\mathbf{E}$ (metal = iron and cobalt).

\section{Introduction}

The outstanding productivities attainable by bis(arylimino)pyridine-iron and bis(arylimino)pyridine-cobalt (pre)catalysts (A, Figure 1) for the polymerization of ethylene, initially reported over twenty years ago [1-4], have spurred a myriad of academic and industrial research disclosures [5-9]. Through systematic variation of the steric and electronic properties of the ligand frame and in particular to the $\mathrm{N}$-aryl groups, catalysts capable of generating highly sought-after materials such as $\alpha$-olefins, linear PE waxes, and high-density polyethylene (HDPE) are all accessible $[2,6,10]$. Moreover, such targeted ligand manipulation has seen remarkable improvements to the temperature stability of the catalyst itself $[5-9,11-14]$, a limitation often levelled against the first-generation catalysts $[4,6]$. Elsewhere, other types of neutral $N, N, N$-ligand skeleton such as $N$-[(pyridin-2-yl)-methylene]-8-amino-quinolines [15], 2-benzimidazolyl-6-imino-pyridines [16-18], 2,8-bis(imino)quinolines [19], and 2-imino-1,10-phenanthrolines $[20,21]$ have witnessed some important developments [6-8]. From a commercial viewpoint, the successful implementation of a 500-ton scale pilot process for the production of linear $\alpha$-olefins (LAOs) in China that makes use of a 2-imino-1,10-phenanthroline-iron catalyst highlights the enormous potential of this homogeneous technology $[6,8,20,21]$.

As an alternative strategy in bis(imino)pyridine ligand design, our group has recently explored the fusion of carbocycles to the central pyridine unit in (Figure 1) as a means to form well-defined Fe-/Co-based complexes bearing singly [22-30] and doubly fused derivatives (e.g., B, C, D, and E in Figure 1) [31-38]. Indeed, the fused ring size has been shown to be pivotal to the catalytic activity and polymeric properties [6, 36-38]. Of particular note, iron-containing B [31], C [32], and $\mathbf{D}$ [36] can produce strictly linear polyethylenes with a wide range of molecular weights, end-group types, and activities (up to $10^{7} \mathrm{~g}(\mathrm{PE}) \mathrm{mol}^{-1}(\mathrm{Fe}) \mathrm{h}^{-1}$ ) $[6,36]$. For example, six-membered $\mathbf{B}$ produced the lowest molecular weight polymer $\left(8 \mathrm{~kg} \mathrm{~mol}^{-1}\right)$ [31], while seven- and eight-membered $\mathbf{C}$ and $\mathbf{D}$ showed a predilection towards higher molecular weight vinyl-polyethylenes (up to $188 \mathrm{~kg} \mathrm{~mol}^{-1}$ ) $[32,36]$. In light of these performance differences, it is probable that the ring size impacts on properties such as the ring flexibility/tension and the overall steric properties of the chelating ligand which in turn influences the propagation and chain transfer steps of polymerization [6]. As a more recent development, we have demonstrated that cobalt-containing $\mathbf{E}$ (Figure 1), incorporating both six- and seven-membered carbocycles, not only showed the highest catalytic activity of the cobalt-containing A-E series but also generated valuable vinyl-terminated PE waxes with narrow molecular weight distributions [38]. Significantly, such low molecular weight polymers provide promising raw materials for the production of functional polymers, copolymers, and coating materials [32, 38].

Given the higher catalytic performance generally achievable for iron over cobalt in ethylene polymerization, [6-8] we now disclose five examples of iron-containing $\mathbf{E}$ (Figure 1) that differ in the steric $\left(\mathrm{R}^{1}=\mathrm{Me}, \mathrm{Et}, i\right.$-Pr) and electronic $\left(\mathrm{R}^{2}=\mathrm{H}\right.$ or $\left.\mathrm{Me}\right)$ properties of their $\mathrm{N}$-aryl groups. Their relative performance as precatalysts in ethylene polymerization is then evaluated using two types of aluminoxane cocatalyst; optimization studies concerned with the amount of aluminoxane cocatalyst employed, run temperature, time, and pressure are also highlighted. Moreover, key comparisons of $\mathbf{E}$ with the parent bis(imino)pyridine-iron $\mathbf{A}$ and its symmetrically fused derivatives $\mathbf{B}, \mathbf{C}$, and $\mathbf{D}$ are made in terms of catalytic performance as well as the properties of the polymer. In addition, full details of the preparation and characterization for the new iron(II) complexes are presented.

\section{Results and Discussion}

2.1. Synthesis and Characterization of the Iron(II) Complexes. Treatment of 2,3,7,8,9,10-hexahydro- $1 \mathrm{H}$-cyclohepta[ $b]$ quinoline-4,6-dione [38] with $\mathrm{FeCl}_{2} \cdot 4 \mathrm{H}_{2} \mathrm{O}$ and four equivalents of the corresponding aniline in acetic acid at reflux for 12 hours gave, on work-up, the 4,6-bis(arylimino)-1,2,3,7,8,9,10-heptahydrocyclohepta[b] quinoline-iron(II) chlorides ( $\operatorname{aryl}=2,6$ $\mathrm{Me}_{2} \mathrm{C}_{5} \mathrm{H}_{3} \quad$ Fel; 2,6- $\mathrm{Et}_{2} \mathrm{C}_{5} \mathrm{H}_{3} \quad$ Fe2; 2,6- $i-\mathrm{Pr}_{2} \mathrm{C}_{5} \mathrm{H}_{3} \quad$ Fe3; 2,4,6- $\mathrm{Me}_{3} \mathrm{C}_{5} \mathrm{H}_{2} \quad$ Fe4; and 2,6- $\mathrm{Et}_{2}-4-\mathrm{MeC}_{5} \mathrm{H}_{2} \quad$ Fe5), in good yields $(68-81 \%)$ (Scheme 1). Such a one-pot 


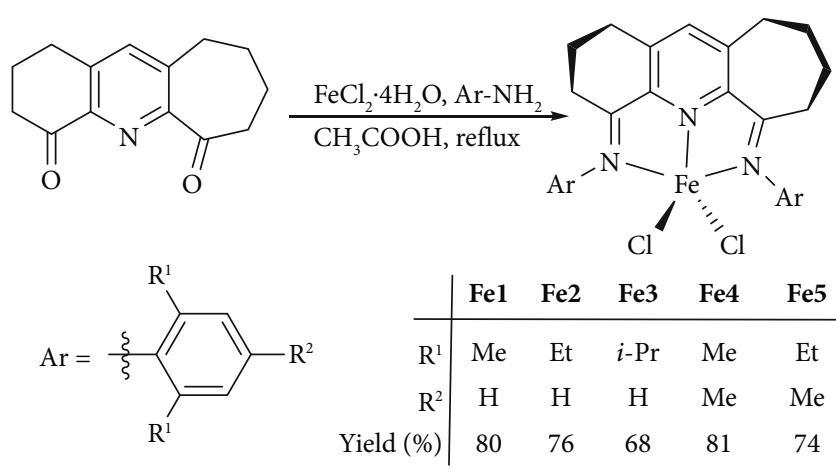

Scheme 1: One-pot route to Fe1-Fe5 from 2,3,7,8,9,10-hexahydro$1 \mathrm{H}$-cyclohepta[$[b]$ quinoline-4,6-dione.

template approach $[31,32,36-38]$ was considered necessary as the free 4,6-bis(arylimino)-1,2,3,7,8,9,10-heptahydrocyclohepta $[b]$ quinolines were not favorable to isolation. All new complexes have been characterized by FT-IR spectroscopy and elemental analysis. In addition, a crystal of Fe3 was the subject of a single crystal X-ray diffraction study.

Single crystals of Fe3 suitable for the X-ray determination were grown under an atmosphere of nitrogen by the slow diffusion of $\mathrm{Et}_{2} \mathrm{O}$ into a $\mathrm{CH}_{2} \mathrm{Cl}_{2}$ solution of the complex maintained at room temperature. A view of Fe3 is depicted in Figure 2; selected bond distances/angles are collected in Table 1. The structure of Fe3 consists of a single iron center surrounded by three nitrogen atoms belonging to the 4,6 bis(2,6-diisopropylphenylimino)-1,2,3,7,8,9,10-heptahydrocyclohepta $[b]$ quinoline and two terminal chlorides to afford a geometry best termed distorted square pyramidal. Specifically, the nitrogen donor atoms $(\mathrm{N} 1, \mathrm{~N} 2$, and N3) of the chelating ligand together with $\mathrm{Cl} 1$ form the square base of the pyramid with $\mathrm{Cl} 2$ occupying the apical position; related arrangements have previously been seen for their ironbased counterparts B-D (Figure 1) [31, 32, 36]. The iron atom in Fe3 lies at a distance of $0.562 \AA$ above the square base, which is slightly shorter than in $\mathbf{D}(0.596 \AA)$ [36] and 2-(1-(arylimino)ethyl)-8-arylimino-5,6,7-trihydroquinolineiron(II) chloride ( $0.583 \AA$ ) [22], while longer than that found in iron complexes bound by 2-(arylimino)-9-arylimino5,6,7,8-tetrahydro-cycloheptapyridines (0.442 and $0.320 \AA$ ) $[26,27]$. Within the $N, N, N-F e$ unit, the $\mathrm{Fe}-\mathrm{N}_{\text {pyridine }}$ bond distance of 2.060(1) $\AA$ is noticeably shorter than the exterior Fe- $\mathrm{N}_{\text {imine }}$ bond lengths of 2.216(1) $\AA$, while the N1-Fe1-N2 and $\mathrm{N} 1-\mathrm{Fe} 1-\mathrm{N} 3$ angles of $74.17(7)^{\circ}$ and $73.10(7)^{\circ}$ are comparable with previous work $[22,26,27,32,36]$. Moreover, the two $\mathrm{Fe}-\mathrm{N}_{\text {imine }}$ bond lengths in $\mathbf{F e} 3$ are slightly shorter when compared with those in C (2.313(4)-2.320(4) $\AA$ ) [32] and D (2.261(2)-2.272(2) ^) [36] but similar to those observed in iron(II)-containing 2-(arylimino)-9-arylimino-5,6,7,8tetrahydro-cycloheptapyridines $(2.210(8)$ and $2.212(9) \AA)$ [26]. Similarly, the $\mathrm{Fe}-\mathrm{N}_{\text {pyridine }}$ distance in $\mathbf{F e} 3$ is shorter than that found in $\mathbf{A}$ [4], $\mathbf{B}$ [31], $\mathbf{C}$ [32], and $\mathbf{D}$ [36] (range: $2.080(4)-2.189(6) \AA$ ) but related to those observed in the 2-(1-(2,6-diethylphenylimino)ethyl)-8-arylimino5,6,7-trihydroquinoline-iron(II) chlorides (2.069(3) Å) [22]. Examination of the $\mathrm{N} 1-\mathrm{C} 1-\mathrm{C} 2-\mathrm{N} 2\left(6.40^{\circ}\right)$ and N1-C9-
$\mathrm{C} 10-\mathrm{N} 3\left(-6.93^{\circ}\right)$ torsion angles highlights the deviation from coplanarity between the pyridine ring and the adjacent imine vectors; a related distorted arrangement of the $N, N, N$-ligand has been noted in its cobalt analogues [38]. The C3-C4-C5 and C11-C12-C13-C14 sections of the two fused carbocyles are puckered as a consequence of the $\mathrm{sp}^{3}$-hybridization of these carbon atoms leading to a cis configuration in which both saturated sections fold towards apical $\mathrm{Cl} 2$. The $\mathrm{N}$-aryl rings are inclined at angles of $88.93^{\circ}\left(\mathrm{N} 2{ }_{6 \text {-membered }}\right)$ and $77.78^{\circ}\left(\mathrm{N} 3_{7-m e m b e r}\right)$ with respect to their neighboring imine vectors, which can be justified in terms of the different steric properties exerted by the 6- and 7-membered rings. Collectively, it would appear that the fused 6- and 7-membered rings in $\mathrm{Fe} 3$ have caused some structural reorganization within the $N, N, N$-ligand which in turn influences the coordination sphere of the complex.

The FT-IR spectra of Fe1-Fe5 revealed stretching frequencies in the range $1604-1614 \mathrm{~cm}^{-1}$ that are quite typical of bound N-imine groups; no absorptions corresponding to the free diketone were detectable [36-39]. Further support for the structural identity of Fe1-Fe5 was provided by the microanalytical data which were in complete agreement with elemental compositions for complexes of general formula $(N, N, N) \mathrm{FeCl}_{2}$.

2.2. Ethylene Polymerization. To investigate the aptitude of Fe1-Fe5 to act as precatalysts for ethylene polymerization, MAO and MMAO were selected as cocatalysts to allow two parallel studies to be performed. Both these types of aluminoxane have been previously shown as among the most effective for precatalyst activation in iron-based polymerization catalysis $[4,6,11,12,26,27,31,32,36]$.

2.2.1. Catalytic Evaluation of Fe1-Fe5 Using MMAO. To establish the optimum reaction conditions for these MMAO-activated polymerizations, $\mathbf{F e} 4$ was chosen as the precatalyst for initial assessment and the amount of aluminoxane cocatalyst ( $\mathrm{Al}: \mathrm{Fe}$ molar ratio), temperature, and run time systematically varied with the ethylene pressure set at either 1,5 , or 10 atm.

Firstly, the runs were performed at 1 atm $\mathrm{C}_{2} \mathrm{H}_{4}$ and the effect of $\mathrm{Al}: \mathrm{Fe}$ molar ratio on the performance of Fe4/MMAO examined (runs 1-5, Table 2). With the reaction temperature kept at $20^{\circ} \mathrm{C}$, the tests were undertaken using different $\mathrm{Al}$ : Fe ratios of 1000, 1500, 2000, 2500, and 3000; the optimum activity of $1.82 \times 10^{6} \mathrm{~g}(\mathrm{PE}) \mathrm{mol}^{-1}(\mathrm{Fe}) \mathrm{h}^{-1}$ was observed at a value of 2500 (run 4 , Table 3 ). The polyethylenes for all five runs were of low molecular weight falling in the range $5.8-15.7 \mathrm{~kg} \mathrm{~mol}^{-1}$; there was no evidence for any short chain oligomers (e.g., from $\mathrm{C}_{4}$ to $\mathrm{C}_{32}$ ). It was also noted that the lowest molecular weight polymer within this range corresponded to the polymerizations conducted with higher $\mathrm{Al}$ : $\mathrm{Fe}$ molar ratios, a finding that can be linked to the higher rate of chain transfer from the iron active species to aluminum on increasing the amount of alkyl aluminum reagent $[26,27,32,36-38,40,41]$. The influence of temperature was then investigated with the $\mathrm{Al}: \mathrm{Fe}$ molar ratio retained at 2500 . By varying the test temperature from 10 to $60^{\circ} \mathrm{C}$ (runs 4 and $6-10$, Table 2), a peak activity of 


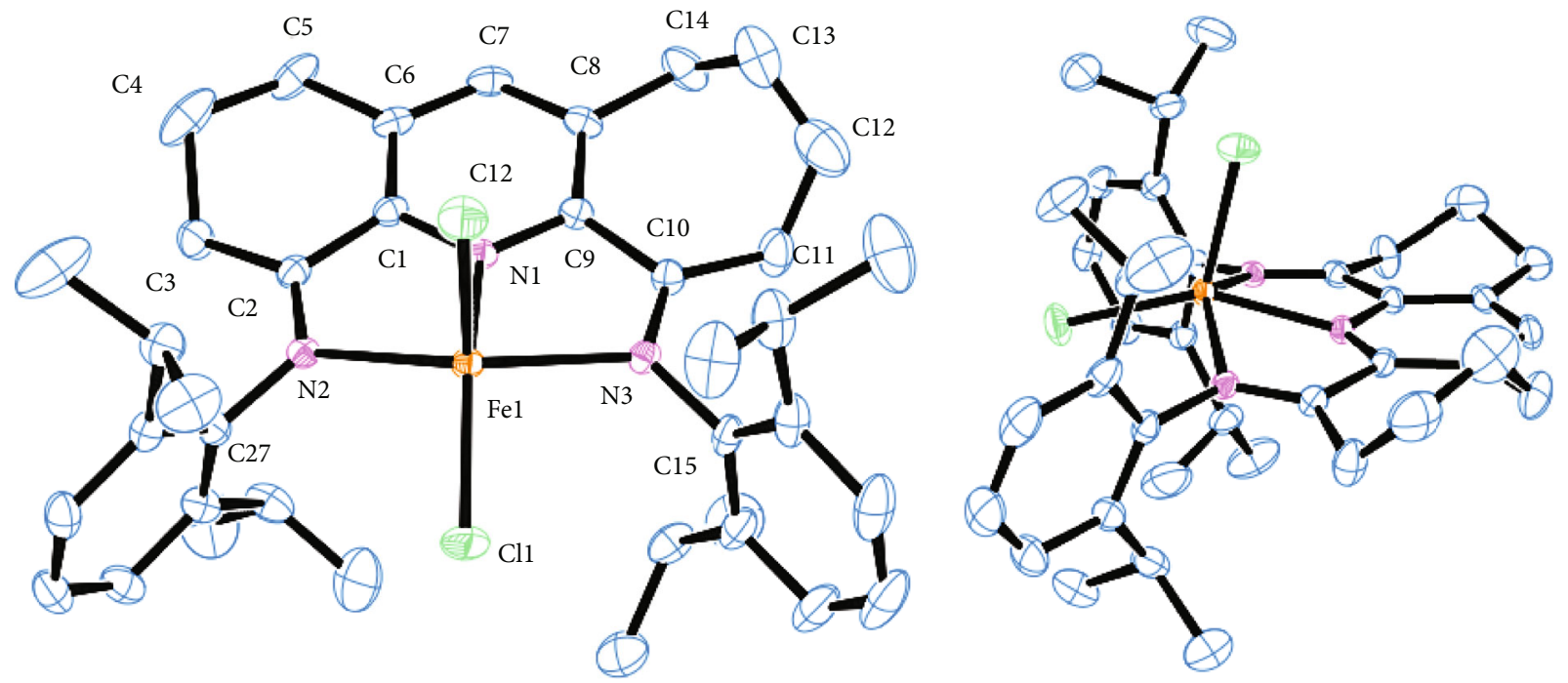

Figure 2: ORTEP representations of Fe3 at the 30\% probability level. Hydrogen atoms have been omitted for clarity.

TABLe 1: Selected bond lengths and angles for Fe3.

\begin{tabular}{lclc}
\hline \multicolumn{2}{c}{ Bond lengths $(\AA)$} & \multicolumn{2}{c}{ Bond angles $\left(^{\circ}\right)$} \\
\hline Fe1-N1 & $2.060(1)$ & N1-Fe1-N2 & $74.17(7)$ \\
Fe1-N2 & $2.216(1)$ & N1-Fe1-N3 & $73.10(7)$ \\
Fe1-N3 & $2.216(1)$ & N1-Fe1-Cl1 & $150.80(6)$ \\
Fe1-Cl1 & $2.231(7)$ & N1-Fe1-Cl2 & $91.57(6)$ \\
Fe2-Cl2 & $2.308(7)$ & N2-Fe1-N3 & $140.70(7)$ \\
N1-C1 & $1.341(3)$ & N2-Fe1-Cl1 & $100.47(5)$ \\
N1-C9 & $1.334(3)$ & N2-Fe1-Cl2 & $102.41(5)$ \\
N2-C2 & $1.283(3)$ & N3-Fe1-Cl1 & $97.59(5)$ \\
N2-C27 & $1.438(3)$ & N3-Fe1-Cl2 & $99.64(5)$ \\
N3-C15 & $1.436(3)$ & Cl1-Fe1-Cl2 & $117.48(3)$ \\
\hline
\end{tabular}

$1.82 \times 10^{6} \mathrm{~g}(\mathrm{PE}) \mathrm{mol}^{-1}(\mathrm{Fe}) \mathrm{h}^{-1}$ was observed at $20^{\circ} \mathrm{C}$. It was also evident that the molecular weight of the polyethylene gradually decreased from 9.5 to $1.2 \mathrm{~kg} \mathrm{~mol}^{-1}$ as the temperature was raised which can be credited to increased chain transfer at higher temperature [4, 22, 26, 27, 32-38]. Meanwhile, the molecular weight distribution narrowed as the temperature was raised $\left(M_{\mathrm{w}} / M_{\mathrm{n}}\right.$ : from 13.2 to 2.2$)$, an observation also noted at higher ethylene pressure (vide infra) and elsewhere [4, 32, 36].

Secondly, Fe4/MMAO was also screened at 10 atm $\mathrm{C}_{2} \mathrm{H}_{4}$; the experimental findings are compiled in Table 3. Bearing in mind the temperature/activity correlations seen at $1 \mathrm{~atm}$ $\mathrm{C}_{2} \mathrm{H}_{4}$, a similar study was performed at $10 \mathrm{~atm}$ with the $\mathrm{Al}$ : Fe molar ratio kept at 2500. On increasing the temperature from 30 to $80^{\circ} \mathrm{C}$ (runs 1-6, Table 3 ), the optimum activity of $15.15 \times 10^{6} \mathrm{~g}(\mathrm{PE}) \mathrm{mol}^{-1}(\mathrm{Fe}) \mathrm{h}^{-1}$ was observed at $40^{\circ} \mathrm{C}$. Notably, only modest reductions were evident at either 30 or $50^{\circ} \mathrm{C}$, with all values falling at the $10^{7} \mathrm{~g}(\mathrm{PE}) \mathrm{mol}^{-1}(\mathrm{Fe}) \mathrm{h}^{-1}$ level. Indeed, only with the temperature above $60^{\circ} \mathrm{C}$ did the activity start to significantly drop, with a relatively low value of $4.49 \times 10^{6} \mathrm{~g}(\mathrm{PE}) \mathrm{mol}^{-1}(\mathrm{Fe}) \mathrm{h}^{-1}$ observable at $80^{\circ} \mathrm{C}$ (run 6 , Table 3). As shown in Figure 3, the molecular weights of the polyethylenes decreased from 59.9 to $1.9 \mathrm{~kg} \mathrm{~mol}^{-1}$ as the temperature was increased from 30 to $80^{\circ} \mathrm{C}$, while the molecular weight distributions ranged from bimodal $\left(\leq 40^{\circ} \mathrm{C}\right)$, with two $M_{\text {pk }}$ peaks (peak 1 and peak 2) clearly visible in their GPC traces (Figure 3), to unimodal $\left(\geq 50^{\circ} \mathrm{C}\right)$ [36]. Moreover, the molecular weight distributions progressively narrowed as the temperature was raised $\left(M_{\mathrm{w}} / M_{\mathrm{n}}\right.$ : from 16.0 to 1.5$)$. To account for the modality variations, it would seem likely that two different chain transfer pathways were occurring at temperatures of $\leq 40^{\circ} \mathrm{C}$ (e.g., $\beta-\mathrm{H}$ elimination and transfer to aluminum) while at $\geq 50^{\circ} \mathrm{C}$ one type of chain transfer was prevalent $[11,13,32,36,37]$.

With the temperature held at $40^{\circ} \mathrm{C}$, the polymerization tests were then executed using five different $\mathrm{Al}: \mathrm{Fe}$ ratios (2000, 2250, 2500, 2750, 3000, and 3250). Inspection of the data indicates that there were only modest effects on the activity across this range in $\mathrm{Al}: \mathrm{Fe}$ ratios (runs 2 and 7-11, Table 3). Nevertheless, the highest value of $15.15 \times$ $10^{6} \mathrm{~g}(\mathrm{PE}) \mathrm{mol}^{-1}(\mathrm{Fe}) \mathrm{h}^{-1}$ was observed at a ratio of 2500 (run 2, Table 3). On the other hand, the GPC traces indicated that the molecular weight of the polymers gradually decreased from 35.5 to $16.7 \mathrm{~kg} \mathrm{~mol}^{-1}$ on increasing the ratio from 2000 to 3250 (Figure 4). As noted at $1 \mathrm{~atm} \mathrm{C}_{2} \mathrm{H}_{4}$, this finding can be ascribed to chain transfer from the active species to aluminum on increasing the amount of MMAO resulting in faster chain termination and lower molecular weight polymers $[4,26,27,32,36,40,41]$. A similar trend has been observed for their symmetrical comparators $\mathbf{B}, \mathbf{C}$, and $\mathbf{D}$ (Figure 1) $[26,27,32,36]$. Notably, bimodal distributions $\left(M_{\mathrm{w}} / M_{\mathrm{n}}\right.$ : from 11.0 to 7.7$)$ were again a characteristic of all these runs with two $M_{\mathrm{pk}}$ peaks (peaks 1 and 2) viewable in their GPC traces (Figure 4) with the higher molecular weight fraction progressively becoming the minor component with larger amounts of MMAO [26, 27, 36, 37]. 
TABLe 2: Catalytic evaluation of Fe4/MMAO at 1 atm $\mathrm{C}_{2} \mathrm{H}_{4}{ }^{a}$.

\begin{tabular}{|c|c|c|c|c|c|c|c|c|}
\hline Run & $\mathrm{Al}: \mathrm{Fe}$ & $T\left({ }^{\circ} \mathrm{C}\right)$ & $t(\min )$ & Mass of PE (g) & Activity $^{b}$ & $M_{\mathrm{w}}{ }^{c}$ & $M_{\mathrm{w}} / M_{n}{ }^{\mathrm{c}}$ & $T_{\mathrm{m}}{ }^{d}$ \\
\hline 1 & 1000 & 20 & 30 & 1.50 & 1.00 & 15.7 & 15.4 & 125.8 \\
\hline 2 & 1500 & 20 & 30 & 1.82 & 1.21 & 14.7 & 15.0 & 125.5 \\
\hline 3 & 2000 & 20 & 30 & 2.41 & 1.61 & 10.8 & 12.4 & 124.4 \\
\hline 4 & 2500 & 20 & 30 & 2.75 & 1.82 & 6.2 & 8.2 & 121.6 \\
\hline 5 & 3000 & 20 & 30 & 1.22 & 0.81 & 5.8 & 7.2 & 121.3 \\
\hline 6 & 2500 & 10 & 30 & 2.45 & 1.63 & 9.5 & 13.5 & 124.4 \\
\hline 7 & 2500 & 30 & 30 & 2.48 & 1.65 & 5.9 & 7.9 & 121.2 \\
\hline 8 & 2500 & 40 & 30 & 1.68 & 1.12 & 1.9 & 2.2 & 121.3 \\
\hline 9 & 2500 & 50 & 30 & 1.53 & 1.02 & 1.8 & 2.6 & 119.3 \\
\hline 10 & 2500 & 60 & 30 & 0.60 & 0.40 & 1.2 & 2.2 & 116.8 \\
\hline
\end{tabular}

${ }^{a}$ Conditions: $3.0 \mu \mathrm{mol}$ of Fe4, $30 \mathrm{~mL}$ of toluene, $1 \mathrm{~atm} \mathrm{C} \mathrm{H}_{4} \cdot{ }^{b}$ Activity in units of $10^{6} \mathrm{~g}(\mathrm{PE}) \mathrm{mol}^{-1}(\mathrm{Fe}) \mathrm{h}^{-1} .{ }^{c}$ Determined by GPC, $M_{\mathrm{w}}$ in units of kg mol ${ }^{-1}$. ${ }^{d}$ Determined by DSC.

TABLE 3: Catalytic evaluation of Fe1-Fe5/MMAO at higher $\mathrm{C}_{2} \mathrm{H}_{4}$ pressure ${ }^{a}$.

\begin{tabular}{|c|c|c|c|c|c|c|c|c|c|c|c|}
\hline \multirow{2}{*}{ Run } & \multirow{2}{*}{ Precat. } & \multirow{2}{*}{$\mathrm{Al}: \mathrm{Fe}$} & \multirow{2}{*}{$t(\min )$} & \multirow{2}{*}{$T\left({ }^{\circ} \mathrm{C}\right)$} & \multirow{2}{*}{ Mass of PE (g) } & \multirow{2}{*}{ Activity $^{b}$} & \multicolumn{2}{|c|}{$M_{\mathrm{pk}}$} & \multirow{2}{*}{$M_{\mathrm{w}}{ }^{c}$} & \multirow{2}{*}{$M_{\mathrm{w}} / M_{\mathrm{n}}{ }^{c}$} & \multirow{2}{*}{$T_{\mathrm{m}}{ }^{d}\left({ }^{\circ} \mathrm{C}\right)$} \\
\hline & & & & & & & Peak 1 & Peak 2 & & & \\
\hline 1 & $\mathrm{Fe} 4$ & 2500 & 30 & 30 & 17.56 & 11.70 & $1.2(51 \%)$ & $33.1(49 \%)$ & 59.9 & 16.0 & 129.6 \\
\hline 2 & $\mathrm{Fe} 4$ & 2500 & 30 & 40 & 22.73 & 15.15 & $2.9(70 \%)$ & $28.8(30 \%)$ & 41.42 & 13.4 & 129.1 \\
\hline 3 & Fe4 & 2500 & 30 & 50 & 17.85 & 11.93 & $3.1(100 \%)$ & & 25.42 & 10.6 & 127.2 \\
\hline 4 & $\mathrm{Fe} 4$ & 2500 & 30 & 60 & 15.72 & 10.48 & $3.5(100 \%)$ & & 18.4 & 7.1 & 126.7 \\
\hline 5 & $\mathrm{Fe} 4$ & 2500 & 30 & 70 & 12.53 & 8.35 & $4.8(100 \%)$ & & 5.6 & 2.0 & 126.5 \\
\hline 6 & $\mathrm{Fe} 4$ & 2500 & 30 & 80 & 6.74 & 4.49 & $1.8(100 \%)$ & & 1.9 & 1.5 & 121.2 \\
\hline 7 & $\mathrm{Fe} 4$ & 2000 & 30 & 40 & 19.25 & 12.33 & $1.4(61 \%)$ & $24.4(39 \%)$ & 35.5 & 11.0 & 129.5 \\
\hline 8 & $\mathrm{Fe} 4$ & 2250 & 30 & 40 & 20.35 & 13.56 & $1.4(62 \%)$ & $23.6(38 \%)$ & 34.3 & 10.4 & 129.2 \\
\hline 9 & $\mathrm{Fe} 4$ & 2750 & 30 & 40 & 21.95 & 14.63 & $1.8(63 \%)$ & $22.9(37 \%)$ & 27.6 & 7.3 & 129.0 \\
\hline 10 & $\mathrm{Fe} 4$ & 3000 & 30 & 40 & 19.75 & 13.16 & $1.7(69 \%)$ & $22.3(31 \%)$ & 21.7 & 8.6 & 128.4 \\
\hline 11 & $\mathrm{Fe} 4$ & 3250 & 30 & 40 & 15.35 & 10.23 & $1.1(76 \%)$ & $22.2(24 \%)$ & 16.7 & 7.7 & 128.1 \\
\hline 12 & $\mathrm{Fe} 4$ & 2500 & 5 & 40 & 9.34 & 37.36 & $2.6(100 \%)$ & & 5.8 & 2.9 & 124.1 \\
\hline 13 & $\mathrm{Fe} 4$ & 2500 & 15 & 40 & 18.56 & 24.74 & $1.4(63 \%)$ & $24.4(37 \%)$ & 31.9 & 10.4 & 128.1 \\
\hline 14 & $\mathrm{Fe} 4$ & 2500 & 45 & 40 & 23.74 & 10.55 & $2.2(58 \%)$ & $31.1(42 \%)$ & 61.5 & 15.0 & 129.7 \\
\hline 15 & $\mathrm{Fe} 4$ & 2500 & 60 & 40 & 25.65 & 8.55 & $1.8(44 \%)$ & $32.1(56 \%)$ & 72.9 & 20.8 & 130.7 \\
\hline $16^{e}$ & $\mathrm{Fe} 4$ & 2500 & 30 & 40 & 12.78 & 8.52 & $1.1(51 \%)$ & $40.8(49 \%)$ & 43.8 & 18.3 & 129.3 \\
\hline 17 & Fe1 & 2500 & 30 & 40 & 23.74 & 15.86 & $1.7(57 \%)$ & $23.6(43 \%)$ & 47.2 & 13.6 & 129.6 \\
\hline 18 & $\mathrm{Fe} 2$ & 2500 & 30 & 40 & 18.42 & 12.28 & $1.2(73 \%)$ & $35.1(27 \%)$ & 47.8 & 16.3 & 129.8 \\
\hline 19 & $\mathrm{Fe} 3$ & 2500 & 30 & 40 & 12.75 & 8.50 & $2.8(56 \%)$ & $56.3(44 \%)$ & 65.6 & 24.7 & 130.0 \\
\hline 20 & $\mathrm{Fe} 5$ & 2500 & 30 & 40 & 15.43 & 10.29 & $1.2(65 \%)$ & $44.7(35 \%)$ & 48.1 & 18.2 & 129.9 \\
\hline
\end{tabular}

${ }^{a}$ Conditions: $3.0 \mu \mathrm{mol}$ of Fe1-Fe5, $100 \mathrm{~mL}$ toluene, 10 atm C ${ }_{2} \mathrm{H}_{4} \cdot{ }^{b}$ Activity in units of $10^{6} \mathrm{~g}(\mathrm{PE}) \mathrm{mol}^{-1}(\mathrm{Fe}) \mathrm{h}^{-1} .{ }^{c}$ Determined by GPC, $M_{\mathrm{w}}$ in units of kg mol ${ }^{-1}$. ${ }^{d}$ Determined by DSC. ${ }^{e} 5 \mathrm{~atm} \mathrm{C}_{2} \mathrm{H}_{4}$.

To investigate the effect of the reaction time on the polymerization, the tests were conducted at run times of between 5 and 60 minutes (runs 2 and 12-15, Table 3) with the $\mathrm{Al}$ : Fe ratio fixed at 2500 and the temperature at $40^{\circ} \mathrm{C}$. A maximum level of activity of $37.36 \times 10^{6} \mathrm{~g}(\mathrm{PE}) \mathrm{mol}^{-1}(\mathrm{Fe}) \mathrm{h}^{-1}$ was attained after 5 minutes (run 12, Table 3 ), which by the 60-minute mark had noticeably lessened to $8.55 \times 10^{6} \mathrm{~g}(\mathrm{PE})$ $\mathrm{mol}^{-1}(\mathrm{Fe}) \mathrm{h}^{-1}$ (run 15, Table 3). This would imply that the active species was rapidly produced following MMAO addition and then suffered gradual deactivation as the time elapsed $[22,24,26,32,36,40,41]$. In addition, the molecular weight of the polymers steadily increased over time $\left(M_{\mathrm{w}}\right.$ : from 5.8 to $\left.72.9 \mathrm{~kg} \mathrm{~mol}^{-1}\right)$ with broad bimodal distributions becoming a key feature of the GPC traces over longer test times; notably, the higher molecular weight fraction became the more significant one with more extended run times (Figure S1). On reduction of the ethylene pressure from 10 to $5 \mathrm{~atm}$, the activity $\left(8.52 \times 10^{6} \mathrm{~g}(\mathrm{PE}) \mathrm{mol}^{-1}(\mathrm{Fe}) \mathrm{h}^{-1}\right)$ dropped by nearly a half (run 16 vs. 3 , Table 3). By comparison, at $1 \mathrm{~atm} \mathrm{C}_{2} \mathrm{H}_{4}$, 


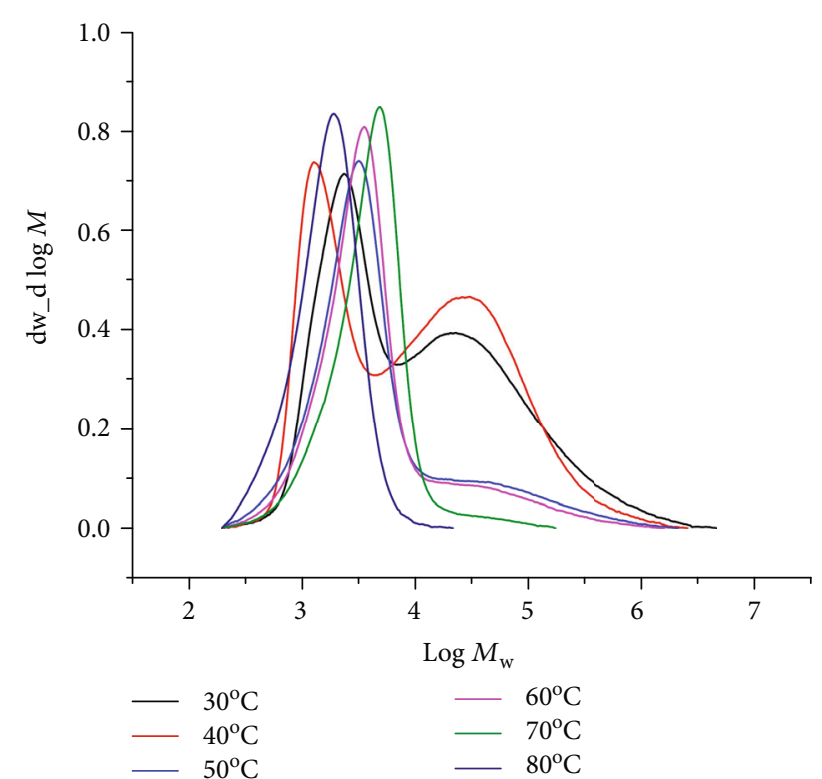

FIgUre 3: GPC traces for the PEs produced using Fe4/MMAO at different reaction temperatures $\left(10 \mathrm{~atm} \mathrm{C}_{2} \mathrm{H}_{4}, \mathrm{Al}: \mathrm{Fe}\right.$ ratio $=2500$, and $30 \mathrm{~min}$; runs $1-6$, Table 3 ).

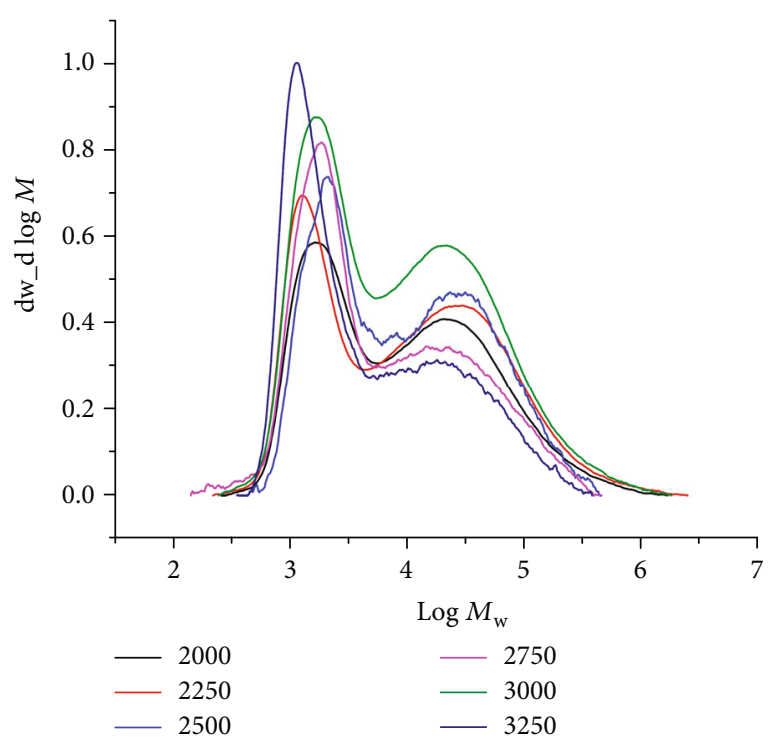

FIgURE 4: GPC traces for the PEs produced using Fe4/MMAO with various $\mathrm{Al}$ : $\mathrm{Fe}$ ratios $\left(10 \mathrm{~atm} \mathrm{C}_{2} \mathrm{H}_{4}, 40^{\circ} \mathrm{C}\right.$, and $30 \mathrm{~min}$; runs 2 and 7-11, Table 3).

the lowest activity $\left(1.82 \times 10^{6} \mathrm{~g}(\mathrm{PE}) \mathrm{mol}^{-}(\mathrm{Fe}) \mathrm{h}^{-1}\right.$, Table 2$)$ was observed which can be credited to the lower ethylene concentration at lower pressure [22, 23, 26, 27, 32, 36-38].

Thirdly, to glean some information as to the effect imparted by the $\mathrm{N}$-aryl groups on performance and polymer properties, Fe1-Fe3 and Fe5 were additionally screened for ethylene polymerization using the optimal conditions found for Fe4/MMAO ( $\mathrm{Al}: \mathrm{Fe}=2500, T=40^{\circ} \mathrm{C}, t=30$ min) (runs 17-20, Table 3 ). As a common observation, the five precatalysts exhibited very high activities (range:

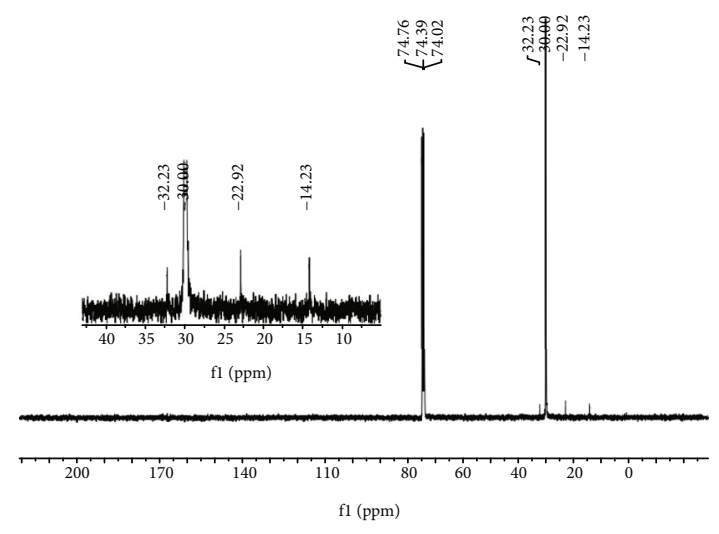

FIgURE 5: ${ }^{13} \mathrm{C}$ NMR spectrum of the polyethylene produced using Fe4/MMAO at $40^{\circ} \mathrm{C}$; recorded in $\mathrm{C}_{2} \mathrm{D}_{2} \mathrm{Cl}_{4}$ at $135^{\circ} \mathrm{C}$ (run 2, Table 3).

$\left.8.50-15.86 \times 10^{6} \mathrm{~g}(\mathrm{PE}) \mathrm{mol}^{-1}(\mathrm{Fe}) \mathrm{h}^{-1}\right)$ and produced polyethylenes with broad bimodal distributions $\left(M_{\mathrm{w}} / M_{\mathrm{n}}\right.$ : from 13.4 to 24.7 ), which is in line with two chain transfer pathways being operational for all systems [26, 27, 32, 33, 36, 37]. In terms of the relative activity, this was found to fall in the order Fel $[2,6-\operatorname{di}(\mathrm{Me})]>\mathbf{F e} 4[2,4,6-\operatorname{tri}(\mathrm{Me})]>\mathbf{F e} 2$ $[2,6-\operatorname{di}(\mathrm{Et})]>\mathrm{Fe} 5 \quad[2,6-\mathrm{di}(\mathrm{Et})-4-\mathrm{Me}]>\mathrm{Fe} 3 \quad[2,6-\operatorname{di}(i-\mathrm{Pr})]$, suggesting that the more bulky $\mathrm{R}^{1}$ substituents (e.g., Fe3, $\mathrm{R}=i$-Pr) slowed down the coordination and insertion of ethylene $[4,32,33,36,37,42]$, while the least bulky ones (e.g., Fe1 and Fe4, R=Me) promoted it. In terms of the para-substituent $\mathrm{R}^{2}$, it would appear that electron-donating groups are detrimental to activity (e.g., Fe1 vs. Fe4 and Fe2 vs. Fe5). As a further point, the polyethylene obtained with the most hindered precatalyst, Fe3 [2,6-di $(i-\mathrm{Pr})]$, exhibited the highest molecular weight $\left(65.6 \mathrm{~kg} \mathrm{~mol}^{-1}\right.$, run 19 , Table 3), which highlights the role of steric factors on influencing the chain transfer process $[22,23,32,36,42]$.

In most cases, the $T_{\mathrm{m}}$ values of the polymers obtained using Fe1-Fe5/MMAO were above $128^{\circ} \mathrm{C}$. As a representative sample, the polyethylene obtained using Fe4/MMAO at $40^{\circ} \mathrm{C}\left(T_{\mathrm{m}}=129.1^{\circ} \mathrm{C}\right.$, entry 2 , Table 3$)$ was characterized by ${ }^{13} \mathrm{C}$ NMR spectroscopy. The spectrum, recorded in 1,1,2,2-tetrachloroethane- $d_{2}\left(\mathrm{C}_{2} \mathrm{D}_{2} \mathrm{Cl}_{4}\right)$ at $135^{\circ} \mathrm{C}$, revealed a high intensity peak around $\delta 30.00$ which is indicative of a highly linear polyethylene (Figure 5) [6, 22, 32, 33, 36-38]. In addition, lower intensity resonances at $\delta 14.23,22.92$, and 32.23 were discernable that could be assigned to a n-propyl end-group (Figure 6) [11, 13, 32, 36-38, 43, 44]. By contrast, there was no evidence for signals corresponding to $i$-butyl end-groups, precluding chain transfer to $\mathrm{Al}(i-\mathrm{Bu})_{3}$ and its derivatives present in MMAO $[11,13,32,36]$, nor was there any detectable evidence for vinylic carbon resonances. Therefore, it would appear that the bimodal polymer generated using Fe4/MMAO (run 2, Table 3) contains substantial amounts of saturated chain ends formed through transfer to selectively $\mathrm{AlMe}_{3}$ and its derivatives present in MMAO [11,36].

Finally, to allow a comparison of the current catalysts (E/MMAO) with previously reported iron systems (A-D, Figure 1), selected catalytic and polymer parameters for 


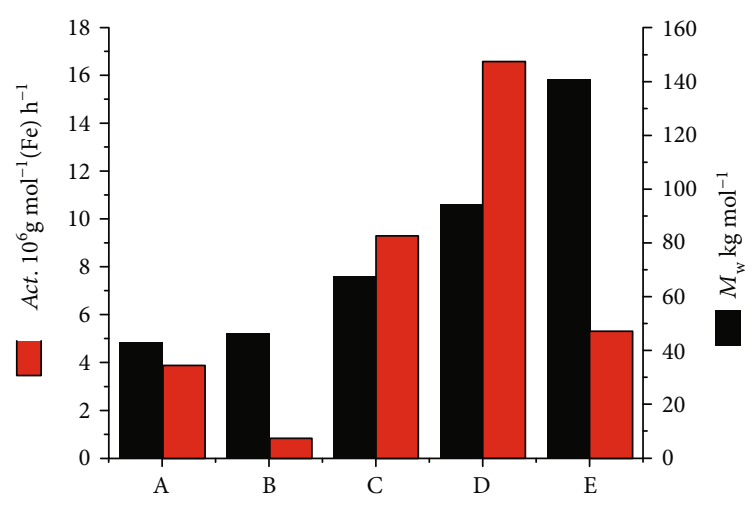

Figure 6: Comparative catalytic performance of $\mathbf{E}_{\mathrm{Me} 2 \mathrm{Ph}}(\mathbf{F e} \mathbf{1})$ with iron precatalysts $\mathbf{A}_{\mathrm{Me} 2 \mathrm{Ph}}$, [4] $\mathbf{B}_{\mathrm{Me} 2 \mathrm{Ph}}$ [31], $\mathbf{C}_{\mathrm{Me} 2 \mathrm{Ph}}$ [32], and $\mathbf{D}_{\mathrm{Me} 2 \mathrm{Ph}}$ [36] (Figure 1); all runs conducted using MMAO, $P_{\mathrm{C} 2 \mathrm{H} 4}=10 \mathrm{~atm}$ and at $40^{\circ} \mathrm{C}$.

polymer samples prepared using $\mathbf{A}_{\mathrm{Me} 2 \mathrm{Ph}} / \mathrm{MMAO}, \mathbf{B}_{\mathrm{Me} 2 \mathrm{Ph}} / \mathrm{M}-$ $\mathrm{MAO}, \mathbf{C}_{\mathrm{Me} 2 \mathrm{Ph}} / \mathrm{MMAO}, \mathbf{D}_{\mathrm{Me} 2 \mathrm{Ph}} / \mathrm{MMAO}$ (Figure 1), and $\left(\mathbf{E}_{\mathrm{Me} 2 \mathrm{Ph}}\right) / \mathrm{MMAO}$ (where $\mathbf{E}_{\mathrm{Me} 2 \mathrm{Ph}}=\mathbf{F e} \mathbf{1}$ ) are displayed alongside each other in Figure 6 (see SI, Tables S1-S5). To maintain consistent conditions for the five catalysts, the polymerization tests for $\mathbf{A}_{\mathrm{Me} 2 \mathrm{Ph}} / \mathrm{MMAO}$ and $\mathbf{B}_{\mathrm{Me} 2 \mathrm{Ph}} / \mathrm{MMAO}$ had to be reperformed at $10 \mathrm{~atm} \mathrm{C}_{2} \mathrm{H}_{4}$ (see SI, Tables S1 and S2) as the original reports used either lower pressure (1.3bar) or MAO as cocatalyst $[4,31]$. All the MMAO-activated systems exhibited very high activities when the polymerization runs were performed at either $40^{\circ} \mathrm{C}$ or $50^{\circ} \mathrm{C}$ (up to $10^{7} \mathrm{~g}(\mathrm{PE}) \mathrm{mol}^{-1}(\mathrm{Fe}) \mathrm{h}^{-1}$ ), with their relative values at $40^{\circ} \mathrm{C}$ following in decreasing order $\mathbf{E}_{\mathrm{Me} 2 \mathrm{Ph}}>\mathbf{D}_{\mathrm{Me} 2 \mathrm{Ph}}>\mathbf{C}_{\mathrm{Me} 2 \mathrm{Ph}}>\mathbf{B}_{\mathrm{Me} 2 \mathrm{Ph}} \sim \mathbf{A}_{\mathrm{Me} 2 \mathrm{Ph}}$. They also produced a range of different types of polymers from polyethylene waxes to high molecular weight polyethylene. Indeed, their molecular weights, as a function of the iron precatalyst, were found to decrease in the order $\mathbf{D}_{\mathrm{Me} 2 \mathrm{Ph}}>\mathbf{C}_{\mathrm{Me} 2 \mathrm{Ph}}>\mathbf{E}_{\mathrm{Me} 2 \mathrm{Ph}}>\mathbf{A}_{\mathrm{Me} 2 \mathrm{Ph}}>\mathbf{B}_{\mathrm{Me} 2 \mathrm{Ph}}$. Strikingly, $\mathbf{E}_{\mathrm{Me} 2 \mathrm{Ph}} / \mathrm{MMAO}$ was the most active catalyst $\left(15.86 \times 10^{6} \mathrm{~g}(\mathrm{PE}) \mathrm{mol}^{-1}(\mathrm{Fe}) \mathrm{h}^{-1}\right.$ at $40^{\circ} \mathrm{C}$, Table S5) and formed polymer with a molecular weight in the midrange of the values. This trend in molecular weight indicates that the smaller the ring size of the carbocycle, the lower the molecular weight of the resultant polyethylene. As would be anticipated, the molecular weight of the polymer produced using the 6/7-membered $\mathbf{E}_{\mathrm{Me} 2 \mathrm{Ph}}$ lies in between that seen for its symmetrical fused-ring comparators $\mathbf{B}_{\mathrm{Me} 2 \mathrm{Ph}}$ $(6 / 6)$ and $C_{\text {Me2Ph }}(7 / 7)$. While steric effects imparted by the fused carbocycle are undoubtedly influential on the molecular weight, it would seem likely that other factors such as ring flexibility and chelation properties also play a role on affecting activity and molecular weight $[6,36,38]$. Pertaining to the dispersity of the polymers, the relatively inflexible $(6 / 6) \quad \mathbf{B}_{\mathrm{Me} 2 \mathrm{Ph}} / \mathrm{MMAO}$ exhibited the narrowest distribution $\left(M_{\mathrm{w}} / M_{\mathrm{n}}=4.5\right)$, while the somewhat more flexible $(6 / 7) \quad \mathbf{E}_{\mathrm{Me} 2 \mathrm{Ph}} / \mathrm{MMAO}\left(M_{\mathrm{w}} / M_{\mathrm{n}}=10.8\right)$ was broader and the most flexible $(8 / 8) \mathbf{D}_{\mathrm{Me} 2 \mathrm{Ph}} / \mathrm{MMAO}$ displayed the broadest $\left(M_{\mathrm{w}} / M_{\mathrm{n}}=28.6\right)$. Overall, these data not only highlight the importance of the fused ring size but also the effect of mixed rings on influencing catalytic performance, molecular weight, and dispersity $[4,6,26,27,32,36,38]$.

2.2.2. Catalytic Evaluation of Fe1-Fe5 Using MAO. As with the Fe/MMAO study, Fe4 was again initially screened this time in combination with $\mathrm{MAO}$ at $1 \mathrm{~atm}$ $\mathrm{C}_{2} \mathrm{H}_{4}$. With the temperature held at $20^{\circ} \mathrm{C}$, the polymerization tests were performed using the different $\mathrm{Al}: \mathrm{Fe}$ ratios, 1000, 1500, 2000, 2500, and 3000; the results are gathered in Table 4 (runs 1-5, Table 5). The best activity $\left(6.53 \times 10^{5} \mathrm{~g}(\mathrm{PE}) \mathrm{mol}^{-1}(\mathrm{Fe}) \mathrm{h}^{-1}\right)$ was observed at an $\mathrm{Al}: \mathrm{Fe}$ ratio of 2000 . The molecular weights of the resultant polymers were found to decrease gradually from 85.4 to $27.6 \mathrm{~kg} \mathrm{~mol}^{-1}$ on raising the $\mathrm{Al}: \mathrm{Fe}$ ratios from 1000 to 3000 . As with the lower pressure runs undertaken using Fe4/MMAO, the polymers generated using Fe4/MAO at 1 atm $\mathrm{C}_{2} \mathrm{H}_{4}$ also displayed broad molecular weight distributions $\left(M_{\mathrm{w}} / M_{\mathrm{n}}=13.7-20.6\right)$ over the range in molar ratios. Meanwhile, an investigation of the reaction temperature was conducted at 1 atm $\mathrm{C}_{2} \mathrm{H}_{4}$ with the $\mathrm{Al}: \mathrm{Fe}$ ratio at 2000. By raising the temperature from 10 to $60^{\circ} \mathrm{C}$ (runs 3 and $6-10$, Table 5), the topmost activity of $12.13 \times 10^{5} \mathrm{~g}(\mathrm{PE}) \mathrm{mol}^{-1}(\mathrm{Fe}) \mathrm{h}^{-1}$ was observed at $30^{\circ} \mathrm{C}$, while at $60^{\circ} \mathrm{C}$ only trace amounts of polymer were detected.

Subsequently, the performance of Fe4/MAO at higher ethylene pressure was carried out; the results are tabulated in Table 4. The influence of reaction temperature was firstly explored at 10 atm $\mathrm{C}_{2} \mathrm{H}_{4}$ with an $\mathrm{Al}$ : Fe molar ratio of 2000. On increasing the reaction temperature from 30 to $90^{\circ} \mathrm{C}$ (runs $1-7$, Table 4), the maximum activity of $9.28 \times 10^{6} \mathrm{~g}(\mathrm{PE}) \mathrm{mol}^{-1}(\mathrm{Fe}) \mathrm{h}^{-1}$ was observed at $60^{\circ} \mathrm{C}$ which represents a higher optimum operating temperature to that seen with Fe4/MMAO; this finding highlights the improved thermal stability of the current catalyst. As borne out by their GPC traces (Figure 7), the molecular weights of the polyethylenes decreased from 64.2 to $7.5 \mathrm{~kg} \mathrm{~mol}^{-1}$ on elevating the temperature from 30 to $90^{\circ} \mathrm{C}$, which as mentioned earlier can be ascribed to temperature-induced chain transfer $[4,26,27,32,33,36,38,40,41]$. As with Fe4/MMAO, the GPC traces obtained using Fe4/MAO over the $30-90^{\circ} \mathrm{C}$ range indicated the distributions to be bimodal-like at temperatures of $\leq 40^{\circ} \mathrm{C}$, while at $\geq 50^{\circ} \mathrm{C}$ they become more unimodal (Figure 7) [36, 37].

With the temperature at $60^{\circ} \mathrm{C}$, the polymerization runs were carried out using different $\mathrm{Al}: \mathrm{Fe}$ ratios of 1250,1500 , $1750,2000,2250$, and 2500 (runs 4 and $8-12$, Table 4). The results indicate little effect on the activity across this range in ratios with the highest value of $9.60 \times 10^{6} \mathrm{~g}(\mathrm{PE}) \mathrm{mol}^{-1}$ $(\mathrm{Fe}) \mathrm{h}^{-1}$ achievable with an $\mathrm{Al}: \mathrm{Fe}$ ratio of 1500 (run 9, Table 4). On the other hand, the molecular weight of the polymeric materials was found to decrease gradually from 21.8 to $15.9 \mathrm{~kg} \mathrm{~mol}^{-1}$ on changing the ratio from 1250 to 2500 (Figure 8), on account of the more rapid chain transfer $[4,26,27,36,37,43-46]$. In comparison with the Fe4/MMAO system, the polymers obtained using Fe4/MAO displayed a narrower molecular weight distribution over the range in molar ratios $\left(M_{\mathrm{w}} / M_{\mathrm{n}}\right.$ range: 3.1-5.1). 
TABLE 4: Catalytic evaluation of Fe1-Fe5/MAO at higher ethylene pressure ${ }^{a}$.

\begin{tabular}{|c|c|c|c|c|c|c|c|c|c|}
\hline Run & Precat. & $\mathrm{Al}: \mathrm{Fe}$ & $t(\min )$ & $T\left({ }^{\circ} \mathrm{C}\right)$ & Mass of PE (g) & Activity $^{b}$ & $M_{\mathrm{w}}{ }^{c}$ & $M_{\mathrm{w}} / M_{\mathrm{n}}{ }^{c}$ & $T_{\mathrm{m}}{ }^{d}\left({ }^{\circ} \mathrm{C}\right)$ \\
\hline 1 & $\mathrm{Fe} 4$ & 2000 & 30 & 30 & 6.28 & 4.18 & 64.2 & 15.3 & 131.3 \\
\hline 2 & $\mathrm{Fe} 4$ & 2000 & 30 & 40 & 10.65 & 7.11 & 47.7 & 8.3 & 131.4 \\
\hline 3 & $\mathrm{Fe} 4$ & 2000 & 30 & 50 & 11.78 & 7.85 & 24.6 & 5.1 & 130.0 \\
\hline 4 & $\mathrm{Fe} 4$ & 2000 & 30 & 60 & 13.78 & 9.28 & 14.2 & 3.8 & 131.0 \\
\hline 5 & $\mathrm{Fe} 4$ & 2000 & 30 & 70 & 12.96 & 8.64 & 9.5 & 3.5 & 128.0 \\
\hline 6 & $\mathrm{Fe} 4$ & 2000 & 30 & 80 & 12.63 & 8.42 & 7.8 & 1.7 & 127.3 \\
\hline 7 & $\mathrm{Fe} 4$ & 2000 & 30 & 90 & 8.16 & 5.44 & 7.5 & 1.6 & 127.9 \\
\hline 8 & $\mathrm{Fe} 4$ & 1250 & 30 & 60 & 13.20 & 8.80 & 21.8 & 3.1 & 130.1 \\
\hline 9 & $\mathrm{Fe} 4$ & 1500 & 30 & 60 & 14.44 & 9.60 & 21.4 & 3.8 & 130.8 \\
\hline 10 & $\mathrm{Fe} 4$ & 1750 & 30 & 60 & 14.02 & 9.34 & 18.0 & 3.7 & 130.1 \\
\hline 11 & $\mathrm{Fe} 4$ & 2250 & 30 & 60 & 12.15 & 8.10 & 15.6 & 4.0 & 130.0 \\
\hline 12 & $\mathrm{Fe} 4$ & 2500 & 30 & 60 & 10.76 & 7.17 & 15.9 & 5.1 & 129.8 \\
\hline 13 & $\mathrm{Fe} 4$ & 1500 & 5 & 60 & 5.36 & 21.44 & 7.5 & 2.1 & 127.7 \\
\hline 14 & $\mathrm{Fe} 4$ & 1500 & 15 & 60 & 9.89 & 13.06 & 13.7 & 2.7 & 128.8 \\
\hline 15 & $\mathrm{Fe} 4$ & 1500 & 45 & 60 & 15.45 & 6.87 & 31.1 & 5.8 & 130.6 \\
\hline 16 & $\mathrm{Fe} 4$ & 1500 & 60 & 60 & 16.18 & 5.39 & 47.8 & 6.7 & 130.9 \\
\hline $17^{e}$ & $\mathrm{Fe} 4$ & 1500 & 30 & 60 & 6.25 & 4.17 & 16.3 & 7.8 & 129.0 \\
\hline 18 & Fe1 & 1500 & 30 & 60 & 14.07 & 9.38 & 30.1 & 5.7 & 130.3 \\
\hline 19 & $\mathrm{Fe} 2$ & 1500 & 30 & 60 & 12.93 & 8.62 & 37.3 & 6.6 & 130.6 \\
\hline 20 & $\mathrm{Fe} 3$ & 1500 & 30 & 60 & 9.12 & 6.08 & 72.6 & 8.1 & 131.4 \\
\hline 21 & $\mathrm{Fe} 5$ & 1500 & 30 & 60 & 13.12 & 8.74 & 44.6 & 9.0 & 130.3 \\
\hline
\end{tabular}

${ }^{a}$ Conditions: $3.0 \mu \mathrm{mol}$ of Fe1-Fe5, $100 \mathrm{~mL}$ toluene, $10 \mathrm{~atm} \mathrm{C}_{2} \mathrm{H}_{4} \cdot{ }^{b}$ Activity in units of $10^{6} \mathrm{~g}(\mathrm{PE}) \mathrm{mol}^{-1}(\mathrm{Fe}) \mathrm{h}^{-1} .{ }^{c}$ Determined by GPC, $M_{\mathrm{w}}$ in units of kg mol ${ }^{-1}$. ${ }^{d}$ Determined by DSC. ${ }^{e} 5 \mathrm{~atm} \mathrm{C}_{2} \mathrm{H}_{4}$.

TABle 5: Catalytic evaluation of Fe4/MAO at 1 atm $\mathrm{C}_{2} \mathrm{H}_{4}{ }^{a}$.

\begin{tabular}{|c|c|c|c|c|c|c|c|c|}
\hline Run & $\mathrm{Al}: \mathrm{Fe}$ & $T\left({ }^{\circ} \mathrm{C}\right)$ & $t(\min )$ & Mass of PE (g) & Activity $^{\mathrm{b}}$ & $M_{\mathrm{w}}{ }^{\mathrm{c}}$ & $M_{\mathrm{w}} / M_{\mathrm{n}}{ }^{\mathrm{c}}$ & $T_{\mathrm{m}}{ }^{\mathrm{d}}$ \\
\hline 1 & 1000 & 20 & 30 & 0.71 & 4.73 & 85.4 & 13.7 & 131.4 \\
\hline 2 & 1500 & 20 & 30 & 0.78 & 5.20 & 53.7 & 13.8 & 131.5 \\
\hline 3 & 2000 & 20 & 30 & 0.98 & 6.53 & 46.9 & 20.6 & 129.6 \\
\hline 4 & 2500 & 20 & 30 & 0.75 & 5.00 & 41.5 & 19.8 & 129.4 \\
\hline 5 & 3000 & 20 & 30 & 0.72 & 4.80 & 27.6 & 16.2 & 129.6 \\
\hline 6 & 2000 & 10 & 30 & 0.82 & 5.47 & 113.3 & 22.6 & 133.4 \\
\hline 7 & 2000 & 30 & 30 & 1.82 & 12.13 & 77.3 & 22.9 & 131.8 \\
\hline 8 & 2000 & 40 & 30 & 1.62 & 10.80 & 31.3 & 15.3 & 128.4 \\
\hline 9 & 2000 & 50 & 30 & 0.32 & 2.13 & 30.6 & 15.6 & 128.7 \\
\hline 10 & 2000 & 60 & 30 & Trace & - & - & - & - \\
\hline
\end{tabular}

Conditions: $3.0 \mu \mathrm{mol}$ of Fe4, $30 \mathrm{~mL}$ of toluene, 1 atm C ${ }_{2} \mathrm{H}_{4} \cdot{ }^{b}$ Activity in units of $10^{5} \mathrm{~g}(\mathrm{PE}) \mathrm{mol}^{-1}(\mathrm{Fe}) \mathrm{h}^{-1} .{ }^{c}$ Determined by GPC, $M_{\mathrm{w}}$ in units of kg mol ${ }^{-1}$. ${ }^{d}$ Determined by DSC.

To facilitate an investigation of the catalytic lifetime of Fe4/MAO, the runs were performed over different reaction times from 5 to 60 minutes at $60^{\circ} \mathrm{C}$ and at an $\mathrm{Al}: \mathrm{Fe}$ ratio of 1500 (runs 9 and 13-16, Table 4). The highest activity of $21.44 \times 10^{6} \mathrm{~g}(\mathrm{PE}) \mathrm{mol}^{-1}(\mathrm{Fe}) \mathrm{h}^{-1}$ was observed after 5 minutes (run 13, Table 4) as was the case with Fe4/MMAO. The activity then gradually decreased to $5.39 \times$ $10^{6} \mathrm{~g}(\mathrm{PE}) \mathrm{mol}^{-1}(\mathrm{Fe}) \mathrm{h}^{-1}$ after 60 minutes (run 16, Table 4) in agreement with gradual deactivation of the active species
$[22,26,27,32,33,36-38,40,41]$. In addition, the molecular weight of the polymers progressively increased $\left(M_{\mathrm{w}}\right.$ : from 7.5 to $47.8 \mathrm{~kg} \mathrm{~mol}^{-1}$ ) over time with a modest broadening in the distributions evident $\left(M_{\mathrm{w}} / M_{\mathrm{n}}\right.$ : from 2.1 to 6.7) (Figure 9). Interestingly, by representing this GPC data as $\mathrm{d} N_{\mathrm{f}}(\mathrm{d} \log M)$ vs. $\log M_{\mathrm{n}}$ plots (Figure S2 in SI), where $\mathrm{d} N_{\mathrm{f}}$ stands for the number fraction of macromolecules having molecular weight $M_{\mathrm{n}}$, some evidence for two types of active sites was evident. In particular, close inspection of Figure S2 reveals a 


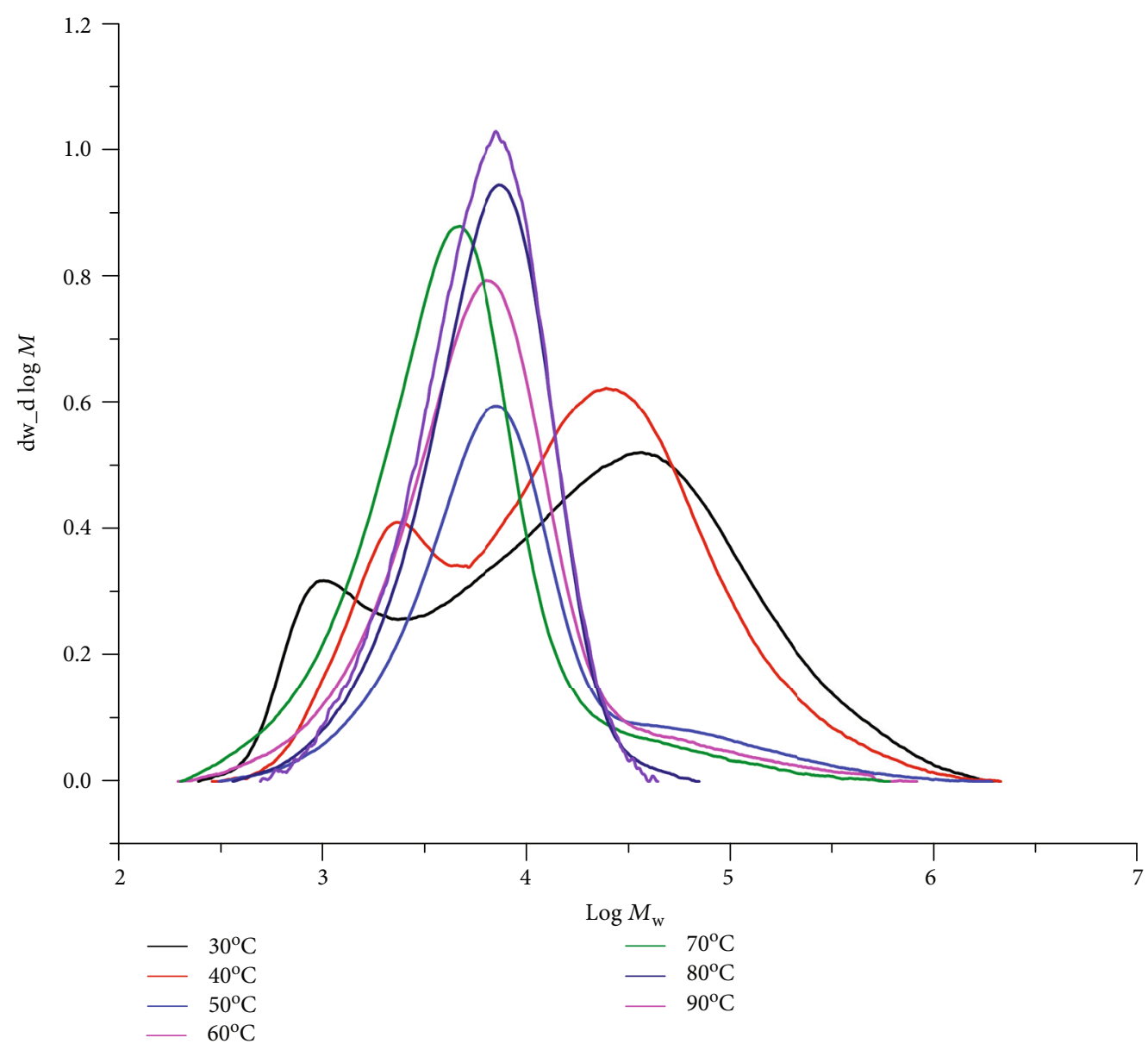

Figure 7: GPC traces for the PEs generated using Fe4/MAO at different reaction temperatures $\left(10\right.$ atm $\mathrm{C}_{2} \mathrm{H}_{4}, \mathrm{Al}: \mathrm{Fe}$ ratio = 2000, and 30 min; runs 1-7, Table 4).

low molecular weight polyethylene that disappeared on prolonged reaction time. This observation may suggest a minor contribution of a second type of active site that gradually reduced as the run proceeded. Nevertheless, a gradual increase of $M_{\mathrm{n}}$ with polymerization time represents the major trend which is in line with a suppression of the chain transfer rate owing to a depletion of the aluminumalkyl chain transfer agent [13]. On lowering the ethylene pressure to $5 \mathrm{~atm}$ (run 17, Table 4), a decline in activity $\left(4.17 \times 10^{6} \mathrm{~g}(\mathrm{PE}) \mathrm{mol}^{-1}(\mathrm{Fe}) \mathrm{h}^{-1}\right)$ was observed (run 17 vs. run 9, Table 4). Such pressure effects can be attributed to the lower solubility of ethylene in toluene at an ambient ethylene pressure as compared to that at higher pressure $[11,32,33,36,43,44]$.

Finally, under the optimized conditions identified for Fe4/MAO ( $\mathrm{Al}: \mathrm{Fe}=1500, T=60^{\circ} \mathrm{C}, t=30$ minutes), the performances of $\mathrm{Fe} 1-\mathrm{Fe} 3$ and $\mathrm{Fe} 5$ were also explored (runs 18-21, Table 4) and the results discussed alongside that for Fe4. In general, these MAO-promoted polymerizations showed high activity though less than that seen with MMAO $\left(6.08-9.60 \times 10^{6} \mathrm{~g}(\mathrm{PE}) \mathrm{mol}^{-1}(\mathrm{Fe}) \mathrm{h}^{-1}\right.$ with MAO vs. $8.50-15.86 \times 10^{6} \mathrm{~g}(\mathrm{PE}) \mathrm{mol}^{-1}(\mathrm{Fe}) \mathrm{h}^{-1}$ with $\left.\mathrm{MMAO}\right)$ with the resulting polyethylenes displaying broad unimodal molecular weight distributions $\left(M_{\mathrm{w}} / M_{\mathrm{n}}=3.8-9.3\right)$. As with Fe1-Fe5/MMAO, a similar trend in activities was apparent, Fe4 $[2,4,6-\operatorname{tri}(\mathrm{Me})]>$ Fe1 $\quad[2,6-\operatorname{di}(\mathrm{Me})]>\mathrm{Fe} 5 \quad[2,6-\mathrm{di}(\mathrm{Et})-4-$ $\mathrm{Me}]>\mathrm{Fe} 2 \quad[2,6-\mathrm{di}(\mathrm{Et})]>\mathrm{Fe} 3 \quad[2,6-\mathrm{di}(i-\mathrm{Pr})]$, with the least sterically bulky Fe4 and Fe1 showing higher activity than the more bulky comparators, Fe2, Fe5, and Fe3. Unlike that seen with MMAO, the para-methyl group in Fe4 and $\mathrm{Fe} 5$ had a positive influence on activity in a manner similar to that described elsewhere [36-38]. In addition, the polyethylene obtained with the most hindered precatalyst Fe3 [2,6-di(i-Pr)] exhibited the highest molecular weight $\left(72.6 \mathrm{~kg} \mathrm{~mol}^{-1}\right.$, run 20 , Table 4) $[32,36-38,43,44]$.

With reference to the polymers generated using Fel$\mathrm{Fe} 5 / \mathrm{MAO}$, the melting temperatures were all around $130^{\circ} \mathrm{C}$ (Table 4) in accord with a highly linear polymeric backbone. This assertion was supported by the ${ }^{1} \mathrm{H}$ and ${ }^{13} \mathrm{C}$ NMR spectra of a sample of polyethylene obtained using $\mathrm{Fe} 4$ at $60^{\circ} \mathrm{C}$ (run 9 , Table 4 ) with a high-intensity single resonance centered around $\delta 30.0$ for the methylene repeat unit in ${ }^{13} \mathrm{C}$ NMR spectrum along with the corresponding peak at $\delta 1.37$ in the ${ }^{1} \mathrm{H}$ NMR spectrum (Figures 10 and 11) $[22,26,27,32$, 33, 36-38]. Interestingly, the ${ }^{13} \mathrm{C}$ NMR spectrum also revealed weaker vinylic carbon resonances $\left(-\mathrm{CH}=\mathrm{CH}_{2}\right)$ at 


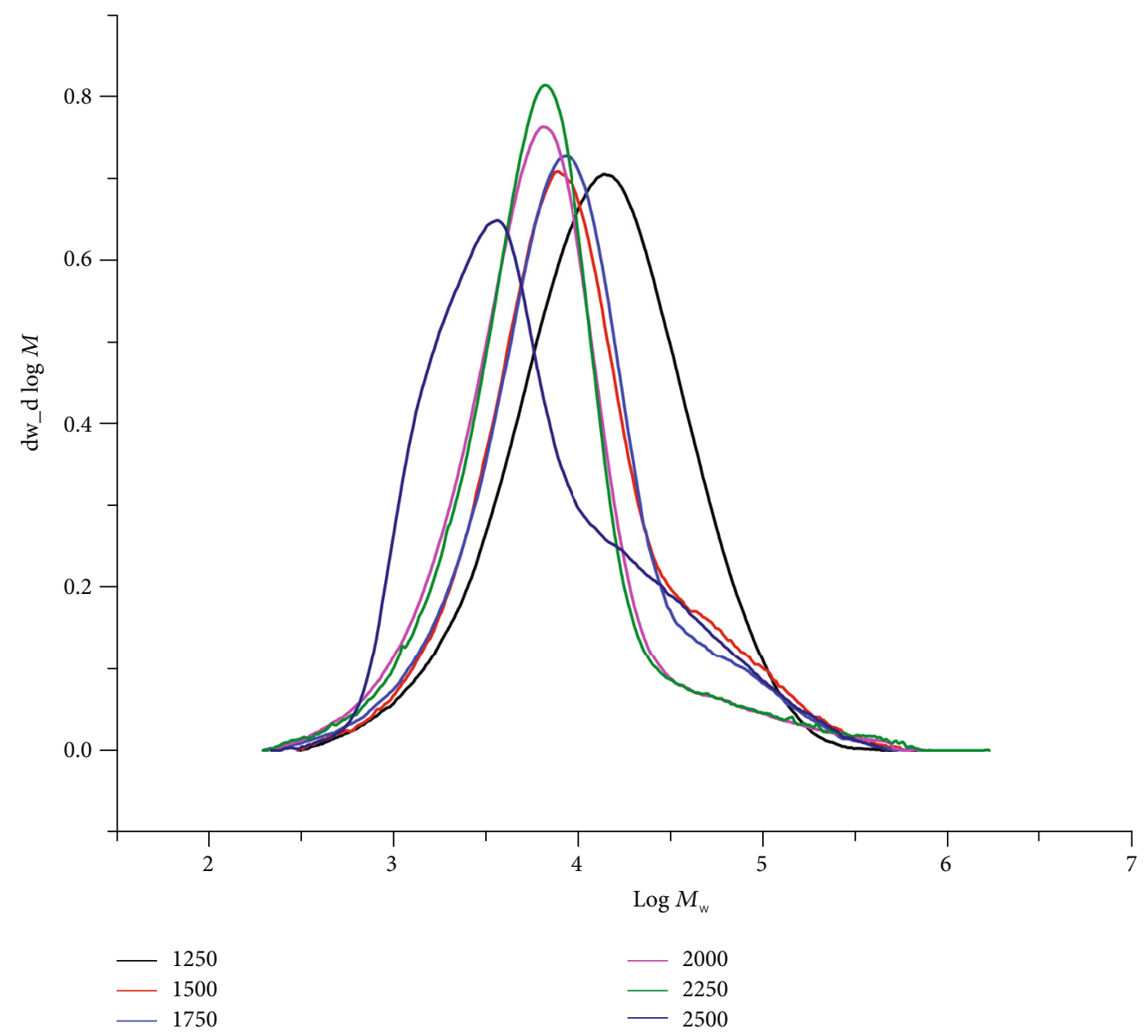

FIgURE 8: GPC traces for the PEs generated using Fe4/MAO with various $\mathrm{Al}$ : Fe ratios $\left(10\right.$ atm $\mathrm{C}_{2} \mathrm{H}_{4}, 60^{\circ} \mathrm{C}$, and 30 min; runs 4 and $8-12$, Table 4).

around $\delta 114.36$ and $\delta 139.49$ along with more upfield $n$-propyl peaks ( $\delta 14.22,22.92$, and 32.24). Support for the presence of a vinyl end-group was further provided by the appearance of downfield proton resonances at $\delta$ 5.01 and $\delta 5.90$ in the ${ }^{1} \mathrm{H}$ NMR spectrum (Figure 11). Based on these NMR observations, it would imply that the main termination pathway in this MAO-promoted polymerization involves $\beta$-hydride elimination $[4,11,32,36,38,43,44]$.

\section{Conclusions}

In summary, a new family of iron(II) chloride complexes of type E (Fe1-Fe5) bound by an unsymmetrical chelating bis(imino)pyridine ligand fused with both six- and sevenmembered carbocyclic rings has been successfully synthesized and fully characterized. Comparison of the structural properties of Fe3 (6/7) with iron comparators containing the symmetrically fused $N, N, N$-ligands, B (6/6), C (7/7), and $\mathbf{D}(8 / 8)$, highlights the effects of variation in ring strain/flexibility as well as steric and chelation properties. Upon treatment with either MMAO or MAO, Fe1-Fe5 showed exceptionally high activities $\left(15.86 \times 10^{6} \mathrm{~g}(\mathrm{PE}) \mathrm{mol}^{-1}(\mathrm{Fe}) \mathrm{h}^{-1}\right.$ at $40^{\circ} \mathrm{C}$ ) for ethylene polymerization forming strictly linear polyethylenes with a broad range of molecular weights. The steric properties of the precatalyst were shown to be influential with the least sterically hindered 2,6- $\mathrm{Me}_{2}$-containing Fel and Fe4 displaying higher activity than the more hindered analogues Fe2 $\left(\mathrm{R}^{1}=\mathrm{Et}\right)$, Fe3 $\left(\mathrm{R}^{1}=i\right.$-Pr $)$, and Fe5 $\left(\mathrm{R}^{1}=\mathrm{Et}\right)$ forming wax-like materials. By contrast, higher molecular weight polymer was obtained with the most sterically encumbered precatalyst Fe3. The polyethylenes were found to display distributions anywhere between narrow unimodal and broad bimodal that could be, to some degree, influenced by the nature/amount of the aluminoxane cocatalyst, temperature, and run time. Moreover, end-group analysis highlighted the role of both $\beta$-H elimination (vinyl chain ends) and chain transfer to aluminum (saturated chain ends) as termination pathways. Overall, these hybrid 6-/7-membered ring catalysts exhibit excellent performance characteristics in ethylene polymerization when compared with iron-based B (6/6), C (7/7), and D (8/8), that can, to some level, be explained in terms of the steric properties imparted by the fused carbocycles and the chelation properties of the $N, N, N$-pincer ligand.

\section{Materials and Methods}

4.1. General Considerations. Synthetic procedures requiring moisture/air-sensitive compounds were performed under nitrogen by using standard Schlenk techniques. Toluene, the solvent used for the polymerization runs, was heated to 


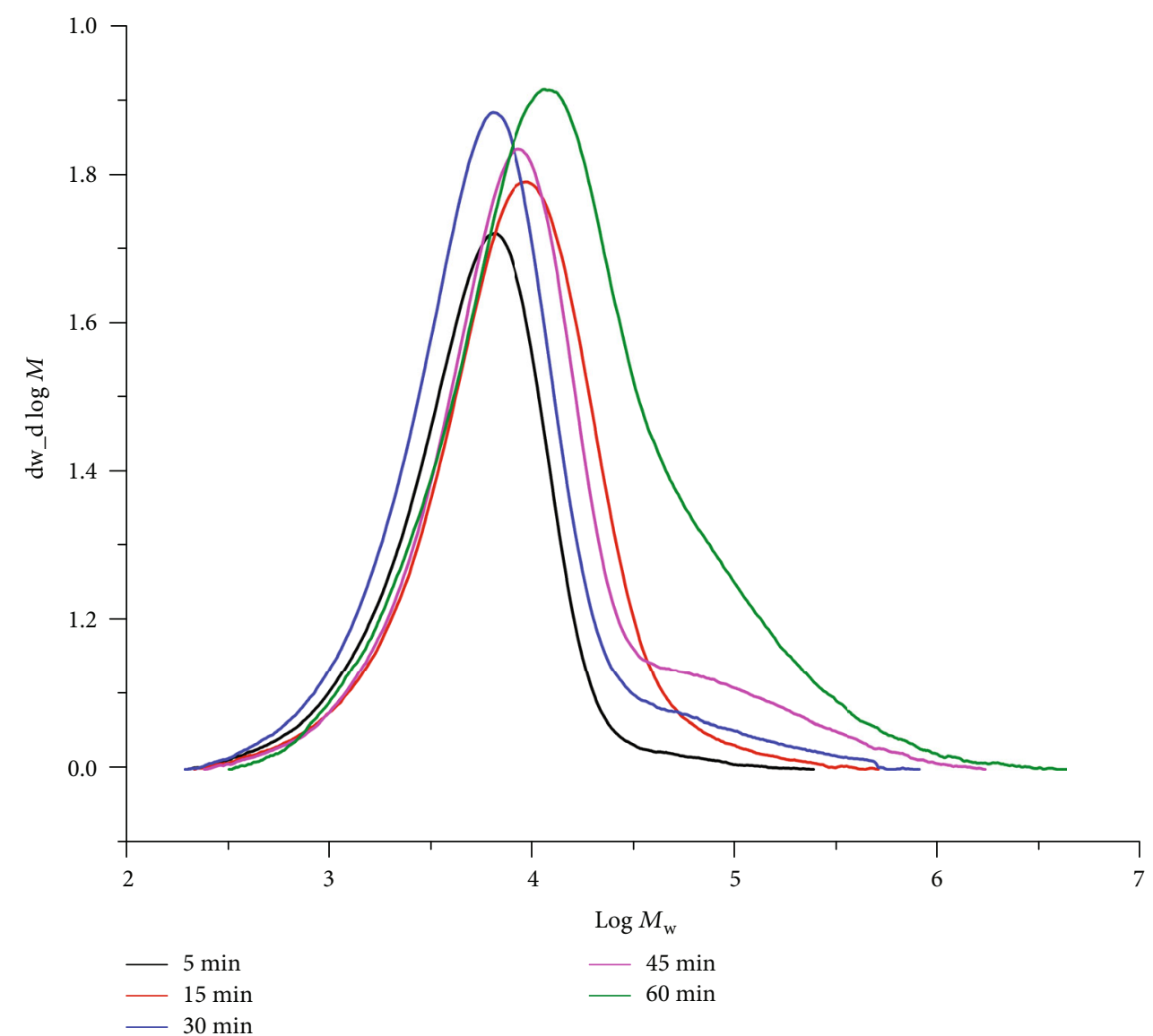

Figure 9: GPC traces for the PEs generated using Fe4/MAO at different reaction times $\left(10 \mathrm{~atm} \mathrm{C}_{2} \mathrm{H}_{4}, 60^{\circ} \mathrm{C}\right.$, and $\mathrm{Al}: \mathrm{Fe}$ ratio $=1500$; runs 9 and 13-16, Table 4).

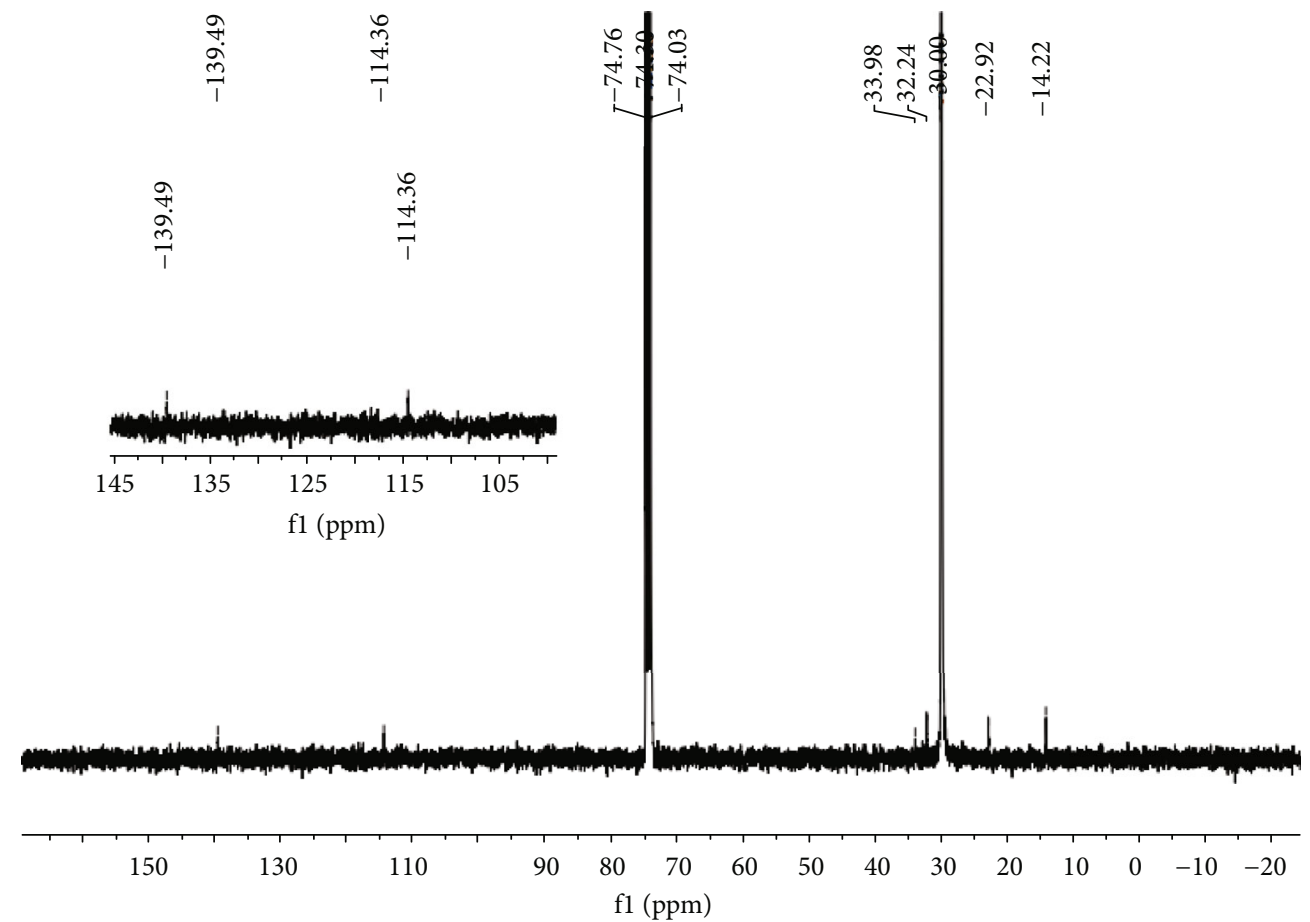

FIgURE 10: ${ }^{13} \mathrm{C}$ NMR spectrum of the polyethylene generated using Fe4/MAO at $60^{\circ} \mathrm{C}$ in $\mathrm{C}_{2} \mathrm{D}_{2} \mathrm{Cl}_{4}$ (run 9, Table 4). 


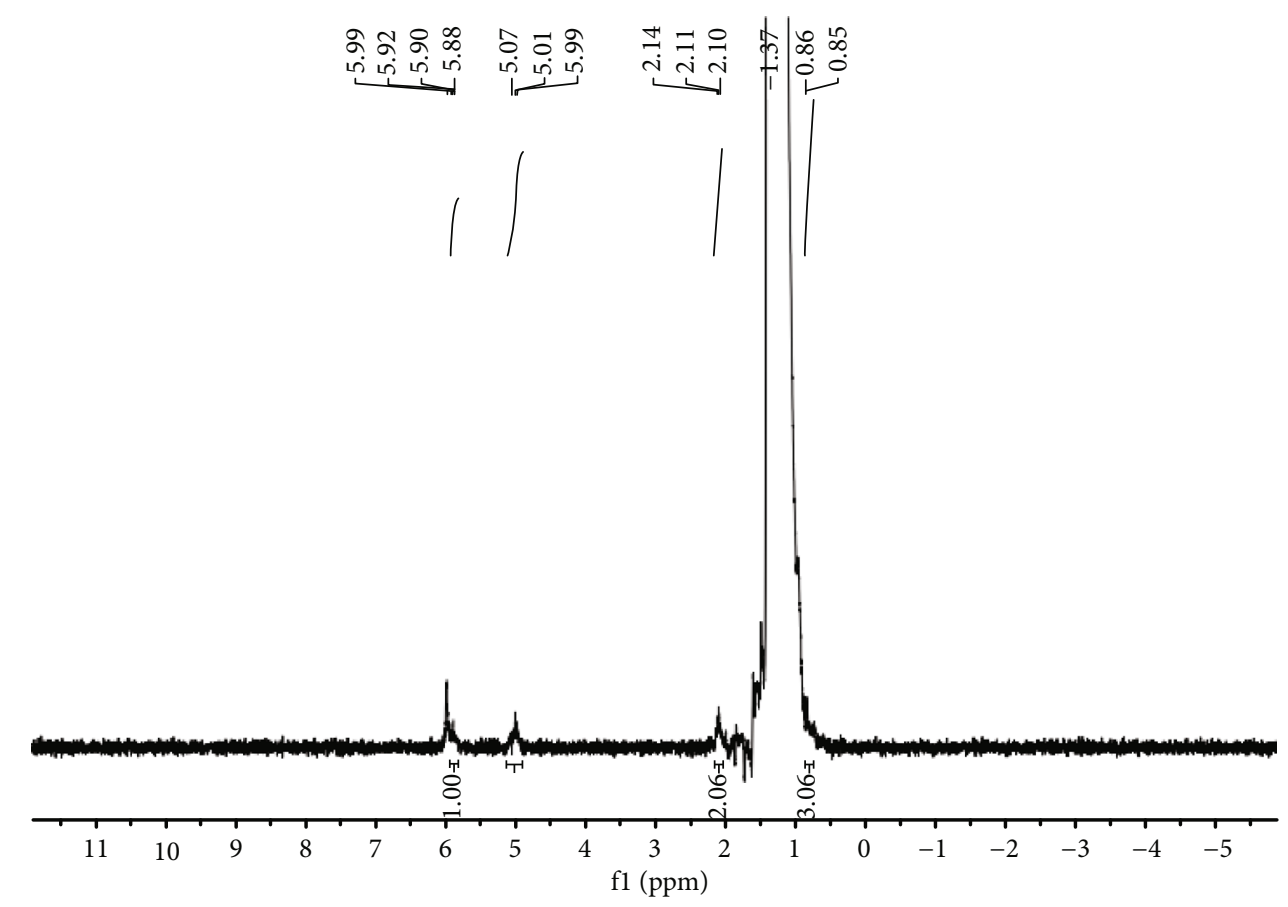

Figure 11: ${ }^{1} \mathrm{H}$ NMR spectrum of the polyethylene generated using Fe4/MAO at $60^{\circ} \mathrm{C}$ in $\mathrm{C}_{2} \mathrm{D}_{2} \mathrm{Cl}_{4}$ (run 9, Table 4).

reflux over sodium and distilled under nitrogen prior to use. Methylaluminoxane (MAO, $1.46 \mathrm{M}$ solution in toluene) and modified methylaluminoxane (MMAO, $1.93 \mathrm{M}$ in $n$-heptane) were acquired from Albemarle Corporation. High-purity ethylene was purchased from Beijing Yanshan Petrochemical Co. and used as received. Other reagents were purchased from Acros, Aldrich, or local suppliers. The properties of the resulting polymeric materials such as melting temperatures $\left(T_{\mathrm{m}}\right)$ were measured by differential scanning calorimetry (DSC), while the molecular weight $\left(M_{\mathrm{w}}\right)$ and dispersity $\left(M_{\mathrm{w}} / M_{\mathrm{n}}\right)$ were determined by gel permeation chromatography (GPC). In selected cases, high-temperature ${ }^{1} \mathrm{H}$ and ${ }^{13} \mathrm{C}$ NMR spectroscopy has also been undertaken to gain further information on the structural properties of the polyolefinic materials; gas chromatography (GC) has been employed in all cases to detect for any short-chain oligomeric fractions (e.g., $\mathrm{C}_{4}-\mathrm{C}_{32}$ ). The ${ }^{1} \mathrm{H}$ and ${ }^{13} \mathrm{C}$ NMR spectra of the polyethylenes were recorded with a Bruker DMX $300 \mathrm{MHz}$ instrument at $135^{\circ} \mathrm{C}$ in $\mathrm{C}_{2} \mathrm{D}_{2} \mathrm{Cl}_{4}$ with TMS as internal standard. Elemental analysis was carried out with a Flash EA 1112 microanalyzer, while the IR spectra were recorded using a Perkin Elmer System 2000 Fourier-Transform infrared (FT-IR) spectrometer. Molecular weights and molecular weight distributions of the polyethylenes were determined with an Agilent PLGPC 220 GPC system at $150^{\circ} \mathrm{C}$ with $1,2,4$-trichlorobenzene as solvent. The melting temperatures of the polyethylenes were measured from the fourth scanning run on a Perkin Elmer TA-Q2000 differential scanning calorimeter under a nitrogen atmosphere. Typically, a sample of about $5.0 \mathrm{mg}$ was heated to $140^{\circ} \mathrm{C}$ at a rate of $20^{\circ} \mathrm{C} \mathrm{min}^{-1}$, maintained for $2 \mathrm{~min}$ at $140^{\circ} \mathrm{C}$ to remove the thermal history, and then cooled to $-40^{\circ} \mathrm{C}$ at a rate of $20^{\circ} \mathrm{Cmin}^{-1}$. The unsymmetrical diketone, 2,3,7,8,9,10-hexahydro-1H-cyclohepta[b]quinoline-4,6-dione, was synthesized using a previously reported procedure [38].

4.2. 4,6-Bis(Arylimino)-1,2,3,7,8,9,10-

HeptahydroCyclohepta[b]-Quinoline-Iron(II) Chlorides (Fe1-Fe5)

4.2.1. Aryl = 2,6- $\mathrm{Me}_{2} \mathrm{C}_{6} \mathrm{H}_{3}$ Fe1. A mixture of 2,3,7,8,9,10-hexahydro-1H-cyclohepta[b]quinoline-4,6-dione $\quad(0.23 \mathrm{~g}$, $1.0 \mathrm{mmol}), 2,6$-dimethylaniline $(0.49 \mathrm{~g}, 4.0 \mathrm{mmol})$, and $\mathrm{FeCl}_{2} \cdot 4 \mathrm{H}_{2} \mathrm{O}(0.19 \mathrm{~g}, 1.0 \mathrm{~mol})$ in glacial $\mathrm{CH}_{3} \mathrm{COOH}(10 \mathrm{~mL})$ was stirred and heated to reflux for $12 \mathrm{~h}$. On cooling to room temperature, an excess of cooled $\mathrm{Et}_{2} \mathrm{O}$ was added to induce precipitation and the precipitate collected by filtration. The solid was dissolved in $\mathrm{MeOH}(5 \mathrm{~mL})$ and the solution then concentrated on the rotary evaporator. $\mathrm{Et}_{2} \mathrm{O}(20 \mathrm{~mL})$ was added to precipitate the product which was collected by filtration and dried under reduced pressure yielding Fel as a blue powder $(0.45 \mathrm{~g}, 80 \%)$. FT-IR $\left(\mathrm{cm}^{-1}\right)$ values are as follows: $772(\mathrm{~s}), 803(\mathrm{w}), 844(\mathrm{w}), 936(\mathrm{w}), 1057(\mathrm{w}), 1109(\mathrm{w}), 1185$ (w), $1248(w), 1361(w), 1383(w), 1460(s), 1569(w), 1605$ $\left(\mathrm{m}, v_{\mathrm{C}=\mathrm{N}}\right), 2866(\mathrm{w}), 2960$ (w). Anal. Calcd for $\mathrm{C}_{30} \mathrm{H}_{33} \mathrm{Cl}_{2} \mathrm{~N}_{3} \mathrm{Fe}(562.36)$ are as follows: $\mathrm{H}, 5.92, \mathrm{C}, 64.07, \mathrm{~N}$, 7.47; found: $H, 6.03, \mathrm{C}, 63.93, \mathrm{~N}, 7.33 \%$.

4.2.2. $\mathrm{Aryl}=2,6-\mathrm{Et}_{2} \mathrm{C}_{6} \mathrm{H}_{3} \mathbf{F e 2}$. By using a similar procedure to that described for $\mathbf{F e} 1, \mathbf{F e} 2$ was isolated as a blue powder $(0.47 \mathrm{~g}, 76 \%)$. FT-IR $\left(\mathrm{cm}^{-1}\right)$ values are as follows: $778(\mathrm{~s})$, $811(\mathrm{~m}), 923(\mathrm{w}), 1058(\mathrm{w}), 1111(\mathrm{w}), 1188(\mathrm{w}), 1240(\mathrm{w})$, $1330(\mathrm{w}), 1452(\mathrm{~s}), 1608\left(\mathrm{~m}, v_{\mathrm{C}=\mathrm{N}}\right), 2873(\mathrm{w}), 2964(\mathrm{~m})$. Anal. 
Calcd for $\mathrm{C}_{34} \mathrm{H}_{41} \mathrm{Cl}_{2} \mathrm{~N}_{3} \mathrm{Fe}$ (618.47) are as follows: $\mathrm{H}, 6.68, \mathrm{C}$, 66.30, N, 6.79; found: $\mathrm{H}, 6.76, \mathrm{C}, 66.14, \mathrm{~N}, 6.63 \%$.

4.2.3. $\mathrm{Aryl}=2,6-i-\mathrm{Pr}_{2} \mathrm{C}_{6} \mathrm{H}_{3} \mathrm{Fe}$. By using a similar procedure to that described for Fe1, Fe3 was isolated as a blue powder $(0.46 \mathrm{~g}, 68 \%)$. FT-IR $\left(\mathrm{cm}^{-1}\right)$ values are as follows: $697(\mathrm{~s})$, 773 (s), $827(\mathrm{w}), 949(\mathrm{w}), 1037(\mathrm{w}), 1091(\mathrm{w}), 1196(\mathrm{w})$, 1235 (w), 1260 (w), 1378 (w), 1466 (s), $1586(\mathrm{w}), 1614$ (m, $v_{\mathrm{C}=\mathrm{N}}$ ), $2863(\mathrm{w}), 2943(\mathrm{w})$. Anal. Calcd for $\mathrm{C}_{38} \mathrm{H}_{49} \mathrm{Cl}_{2} \mathrm{~N}_{3} \mathrm{Fe}$ (674.58) are as follows: $\mathrm{H}, 7.32, \mathrm{C}, 67.66, \mathrm{~N}, 6.23$; found: $\mathrm{H}$, 7.46, C, 67.54, N, 6.13\%.

4.2.4. $\mathrm{Aryl}=2,4,6-\mathrm{Me}_{3} \mathrm{C}_{6} \mathrm{H}_{2} \mathrm{Fe}$. By using a similar procedure to that described for $\mathbf{F e 1}, \mathbf{F e} 4$ was isolated as a blue powder $(0.48 \mathrm{~g}, 81 \%)$. FT-IR $\left(\mathrm{cm}^{-1}\right)$ values are as follows: $716(\mathrm{w})$, $737(\mathrm{~m}), 823$ (w), $854(\mathrm{~s}), 911(\mathrm{w}), 953(\mathrm{w}), 1014(\mathrm{w}), 1039$ (w), $1083(\mathrm{w}), 1154(\mathrm{w}), 1216(\mathrm{~m}), 1371(\mathrm{w}), 1429(\mathrm{~s}), 1536$ (m), $1608(\mathrm{~m}, \mathrm{C}=\mathrm{N}), 2860$ (w), 2916 (w). Anal. Calcd for $\mathrm{C}_{32} \mathrm{H}_{37} \mathrm{Cl}_{2} \mathrm{~N}_{3} \mathrm{Fe}(590.41)$ are as follows: $\mathrm{H}, 6.32, \mathrm{C}, 65.10, \mathrm{~N}$, 7.12; found: $\mathrm{H}, 6.46, \mathrm{C}, 65.04, \mathrm{~N}, 7.05 \%$.

4.2.5. Aryl $=2,6-E t_{2}-4-M e C_{6} H_{2}$ Fe5. By using a similar procedure to that described for Fe1, Fe5 was isolated as a blue powder $(0.48 \mathrm{~g}, 74 \%)$. FT-IR $\left(\mathrm{cm}^{-1}\right)$ values are as follows: $856(\mathrm{~s}), 949(\mathrm{w}), 1058(\mathrm{w}), 1150(\mathrm{w}), 1207(\mathrm{w}), 1262(\mathrm{w})$, $1338(\mathrm{w}), 1454(\mathrm{~s}), 1565(\mathrm{w}), 1604\left(\mathrm{~m}, v_{\mathrm{C}=\mathrm{N}}\right), 2870(\mathrm{w})$, 2931 (w), 2964 (w). Anal. Calcd for $\mathrm{C}_{35} \mathrm{H}_{43} \mathrm{Cl}_{2} \mathrm{~N}_{3} \mathrm{Fe}(645.23)$ are as follows: $\mathrm{H}, 7.02, \mathrm{C}, 66.88, \mathrm{~N}, 6.50$; found: $\mathrm{H}, 7.09, \mathrm{C}$, $66.74, \mathrm{~N}, 6.56 \%$.

\subsection{Polymerization Studies}

4.3.1. Ethylene Polymerization at $P_{\mathrm{C} 2 \mathrm{H} 4}=1 \mathrm{~atm}$. A $100 \mathrm{~mL}$ Schlenk tube, equipped with a stirrer, was employed for the lower pressure polymerization runs. Under an atmosphere of $\mathrm{C}_{2} \mathrm{H}_{4}, \mathrm{Fe} 4(3.0 \mu \mathrm{mol})$ was added followed by toluene $(30 \mathrm{~mL})$ and then the required amount of cocatalyst (MAO, MMAO) introduced by using a syringe. The solution was then stirred at $1 \mathrm{~atm} \mathrm{C}_{2} \mathrm{H}_{4}$ with the temperature set at the required value. After $30 \mathrm{~min}$, the pressure was released and the reaction mixture quenched with $30 \mathrm{~mL}$ of $\mathrm{C}_{2} \mathrm{H}_{5} \mathrm{OH}$ $(10 \% \mathrm{HCl})$. The polymer was washed with $\mathrm{C}_{2} \mathrm{H}_{5} \mathrm{OH}$, dried under reduced pressure at $50^{\circ} \mathrm{C}$, and weighed.

4.3.2. Ethylene Polymerization at $P_{\mathrm{C} 2 \mathrm{H} 4}=5$ or $10 \mathrm{~atm}$. A $250 \mathrm{~mL}$ stainless steel autoclave, equipped with a mechanical stirrer, a temperature controller, and an ethylene pressure control system, was employed for the higher pressure polymerization runs ( 5 or 10 atm $\mathrm{C}_{2} \mathrm{H}_{4}$ ). The autoclave was evacuated and refilled with ethylene three times. Firstly, when the required temperature was reached, the selected iron complex $(3 \mu \mathrm{mol})$, dissolved in toluene $(30 \mathrm{~mL})$, was injected into the autoclave under an atmosphere of ethylene ( $c a .1 \mathrm{~atm})$, followed by the addition of more toluene $(30 \mathrm{~mL})$. Secondly, the required amount of cocatalyst (MAO and MMAO) and additional toluene were added successively by syringe taking the total volume of solvent to $100 \mathrm{~mL}$. The autoclave was immediately pressurized with 5 or $10 \mathrm{~atm}$ ethylene, and the stirring commenced. After the required reaction time $(5,10,30,45$, and $60 \mathrm{~min})$, the reactor was cooled to room temperature with a water bath and the excess ethylene pressure vented. The reaction was quenched with $30 \mathrm{~mL}$ of $\mathrm{C}_{2} \mathrm{H}_{5} \mathrm{OH}(10 \% \mathrm{HCl})$. The polymer was collected and washed with $\mathrm{C}_{2} \mathrm{H}_{5} \mathrm{OH}$ and dried under reduced pressure at $50^{\circ} \mathrm{C}$ and weighed.

4.4. X-Ray Structure Determination. X-ray diffraction (XRD) was employed to determine the molecular structure of Fe3. The XRD patterns were conducted on a Rigaku Sealed Tube CCD (Saturn 724+) diffractometer with graphitemonochromated Mo-K $\alpha$ radiation $(\lambda=0.71073 \AA)$ at $173(2) \mathrm{K}$, and the cell parameters were obtained by global refinement of the positions of all collected reflections. Intensities were corrected for Lorentz and polarization effects and empirical absorption. The structures were solved by direct methods and refined by full-matrix least-squares on $F^{2}$. All nonhydrogen atoms were refined anisotropically, and all hydrogen atoms were placed in calculated positions. Structure solution and structure refinement were performed using SHELXT-2015 [47, 48]. Crystal data and processing parameters for Fe3 are summarized in Table S6.

\section{Data Availability}

All data is available in the main text or the Supplementary Materials.

\section{Conflicts of Interest}

The authors declare no competing financial interest.

\section{Authors' Contributions}

Wen-Hua Sun and Gregory A. Solan conceived the idea of the scheme; Zheng Wang and Qingbin Liu designed the synthetic experiment; Zheng Wang and Yanping Ma performed the ethylene polymerization and characterized the polymers; Tongling Liang conducted the single crystal X-ray diffraction and structure determination; Zheng Wang, Gregory A. Solan, and Wen-Hua Sun wrote the manuscript; Wen-Hua Sun supervised the overall project.

\section{Acknowledgments}

This work was supported by the National Natural Science Foundation of China (No. 21871275). GAS thanks the Chinese Academy of Sciences for a Visiting Fellowship.

\section{Supplementary Materials}

Table S1: polymerization screening using $\mathbf{A}_{\mathrm{Me} 2 \mathrm{Ph}} / \mathrm{MMAO}$ (rescreened in Sun lab at $10 \mathrm{~atm}$ ). Table S2: polymerization screening using $\mathbf{B}_{\mathrm{Me} 2 \mathrm{Ph}} / \mathrm{MMAO}$ (rescreened in Sun lab at $10 \mathrm{~atm})$. Table S3: polymerization screening using $\mathrm{C}_{\mathrm{Me} 2 \mathrm{Ph}} / \mathrm{MMAO}$. Table S4: polymerization screening using $\mathbf{D}_{\mathrm{Me} 2 \mathrm{Ph}} / \mathrm{MMAO}$. Table S5: polymerization screening using Fe1 $\left(\mathbf{E}_{\mathrm{Me} 2 \mathrm{Ph}}\right) / \mathrm{MMAO}$. Table S6: crystal data and structure refinement for Fe3. Figure S1: GPC traces $\left(\mathrm{d} W_{\mathrm{f}} /(\mathrm{d} \log M)\right.$ vs. $\log M$ ) for the $\mathrm{PEs}$ produced using Fe4/MMAO at different reaction times $\left(10\right.$ atm $\mathrm{C}_{2} \mathrm{H}_{4}, 40^{\circ} \mathrm{C}$, and $\mathrm{Al}:$ Fe ratio $=2500$; 
runs 2 and $12-15$, Table 3$)$. Figure S2: GPC traces $\left(\mathrm{d} N_{\mathrm{f}} /(\mathrm{d} \log \right.$ $\left.M_{\mathrm{n}}\right)$ vs. $\log M_{\mathrm{n}}$ ) for the PEs generated using Fe4/MAO at different reaction times $\left(10 \mathrm{~atm} \mathrm{C}_{2} \mathrm{H}_{4}, 60^{\circ} \mathrm{C}\right.$, and $\mathrm{Al}: \mathrm{Fe}$ ratio = 1500; runs 13-16, Table 4). The corresponding GPC traces, represented using $\mathrm{d} W_{\mathrm{f}} /(\mathrm{d} \log M)$ vs. $\log M$, are shown in Figure 9. (Supplementary Materials)

\section{References}

[1] B. L. Small, M. Brookhart, and A. M. A. Bennett, "Highly active iron and cobalt catalysts for the polymerization of ethylene," Journal of the American Chemical Society, vol. 120, no. 16, pp. 4049-4050, 1998.

[2] B. L. Small and M. Brookhart, "Iron-based catalysts with exceptionally high activities and selectivities for oligomerization of ethylene to linear $\alpha$-olefins," Journal of the American Chemical Society, vol. 120, no. 28, pp. 7143-7144, 1998.

[3] G. J. P. Britovsek, V. C. Gibson, S. J. McTavish et al., "Novel olefin polymerization catalysts based on iron and cobalt," Chemical Communications, no. 7, pp. 849-850, 1998.

[4] G. J. P. Britovsek, M. Bruce, V. C. Gibson et al., "Iron and cobalt ethylene polymerization catalysts bearing 2,6-bis(imino)pyridyl ligands: synthesis, structures, and polymerization studies," Journal of the American Chemical Society, vol. 121, no. 38, pp. 8728-8740, 1999.

[5] N. E. Mitchell and B. K. Long, "Recent advances in thermally robust, late transition metal-catalyzed olefin polymerization," Polymer International, vol. 68, no. 1, pp. 14-26, 2019.

[6] Z. Wang, G. A. Solan, W. Zhang, and W.-H. Sun, "Carbocyclic-fused N,N,N-pincer ligands as ring-strain adjustable supports for iron and cobalt catalysts in ethylene oligo/polymerization," Coordination Chemistry Reviews, vol. 363, pp. 92-108, 2018.

[7] Z. Flisak and W.-H. Sun, "Progression of diiminopyridines: from single application to catalytic versatility," ACS Catalysis, vol. 5, no. 8, pp. 4713-4724, 2015.

[8] J. Ma, C. Feng, S. Wang et al., "Bi- and tri-dentate imino-based iron and cobalt pre-catalysts for ethylene oligo-/polymerization," Inorganic Chemistry Frontiers, vol. 1, no. 1, pp. 14-34, 2014.

[9] W. Zhang, W. H. Sun, and C. Redshaw, "Tailoring iron complexes for ethylene oligomerization and/or polymerization," Dalton Transactions, vol. 42, no. 25, pp. 8988-8997, 2013.

[10] G. J. P. Britovsek, S. Mastroianni, G. A. Solan et al., "Oligomerisation of ethylene by bis(imino)pyridyliron and -cobalt complexes," Chemistry - A European Journal, vol. 6, no. 12, pp. 2221-2231, 2000.

[11] Q. Mahmood, J. Guo, W. Zhang, Y. Ma, T. Liang, and W.H. Sun, "Concurrently improving the thermal stability and activity of ferrous precatalysts for the production of saturated/unsaturated polyethylene," Organometallics, vol. 37, no. 6, pp. 957-970, 2018.

[12] Q. Mahmood, E. Yue, J. Guo et al., "Nitro-functionalized bis(imino)pyridylferrous chlorides as thermo-stable precatalysts for linear polyethylenes with high molecular weights," Polymer, vol. 159, pp. 124-137, 2018.

[13] N. V. Semikolenova, W.-H. Sun, I. E. Soshnikov et al., "Origin of "multisite-like" ethylene polymerization behavior of the single-site nonsymmetrical bis(imino)pyridine iron(II) complex in the presence of modified methylaluminoxane," ACS Catalysis, vol. 7, no. 4, pp. 2868-2877, 2017.

[14] L. Guo, M. Zada, W. Zhang et al., "Highly linear polyethylenes tailored with 2,6-bis[1-(p-dibenzo-cycloheptylarylimino)ethyl]pyridylcobalt dichlorides," Dalton Transactions, vol. 48, no. 17, pp. 5604-5613, 2019.

[15] K. Wang, K. Wedeking, W. Zuo, D. Zhang, and W.-H. Sun, "Iron(II) and cobalt(II) complexes bearing N-((pyridin-2yl)methylene)-quinolin-8-amine derivatives: synthesis and application to ethylene oligomerization," Journal of Organometallic Chemistry, vol. 693, no. 6, pp. 1073-1080, 2008.

[16] L. Xiao, R. Gao, M. Zhang, Y. Li, X. Cao, and W.-H. Sun, "2(1H-2-Benzimidazolyl)-6-(1- (arylimino)ethyl)pyridyl iro$\mathrm{n}$ (II) and cobalt(II) dichlorides: syntheses, characterizations, and catalytic behaviors toward ethylene reactivity," Organometallics, vol. 28, no. 7, pp. 2225-2233, 2009.

[17] W.-H. Sun, P. Hao, S. Zhang et al., "Iron(II) and cobalt(II) 2(benzimidazolyl)-6-(1-(arylimino)ethyl)pyridyl complexes as catalysts for ethylene oligomerization and polymerization," Organometallics, vol. 26, no. 10, pp. 2720-2734, 2007.

[18] Y. Huang, R. Zhang, T. Liang, X. Hu, G. A. Solan, and W.H. Sun, "Selectivity effects on $N, N, N^{\prime}$-Cobalt catalyzed ethylene dimerization/trimerization dictated through choice of aluminoxane cocatalyst," Organometallics, vol. 38, no. 5, pp. 1143-1150, 2019.

[19] S. Zhang, W.-H. Sun, T. Xiao, and X. Hao, "Ferrous and cobaltous chlorides bearing 2,8-bis(imino)quinolines: highly active catalysts for ethylene polymerization at high temperature," Organometallics, vol. 29, no. 5, pp. 1168-1173, 2010.

[20] L. Wang, W.-H. Sun, L. Han, H. Yang, Y. Hu, and X. Jin, "Late transition metal complexes bearing 2,9-bis(imino)-1,10-phenanthrolinyl ligands: synthesis, characterization and their ethylene activity," Journal of Organometallic Chemistry, vol. 658, no. 1-2, pp. 62-70, 2002.

[21] W.-H. Sun, S. Jie, S. Zhang et al., "Iron complexes bearing 2imino-1,10-phenanthrolinyl ligands as highly active catalysts for ethylene oligomerization," Organometallics, vol. 25, no. 3, pp. 666-677, 2006.

[22] W. Zhang, W. Chai, W.-H. Sun, X. Hu, C. Redshaw, and X. Hao, "2-(1-(Arylimino)ethyl)-8-arylimino-5,6,7-trihydroquinoline Iron(II) chloride complexes: synthesis, characterization, and ethylene polymerization behavior," Organometallics, vol. 31, no. 14, pp. 5039-5048, 2012.

[23] W.-H. Sun, S. Kong, W. Chai et al., "2-(1-(Arylimino)ethyl)-8arylimino-5,6,7-trihydroquinolylcobalt dichloride: synthesis and polyethylene wax formation," Applied Catalysis A: General, vol. 447-448, pp. 67-73, 2012.

[24] J. Ba, S. Du, E. Yue, X. Hu, Z. Flisak, and W.-H. Sun, "Constrained formation of 2-(1-(arylimino)ethyl)-7-arylimino6,6-dimethylcyclopentapyridines and their cobalt(II) chloride complexes: synthesis, characterization and ethylene polymerization," RSC Advances, vol. 5, no. 41, pp. 32720-32729, 2015.

[25] Y. Zhang, C. Huang, X. Hao, X. Hu, and W.-H. Sun, “Accessing highly linear polyethylenes by 2-(1-aryliminoethyl)-7arylimino-6,6-dimethylcyclopenta[b]pyridylchromium (III) chlorides," RSC Advances, vol. 6, no. 94, pp. 91401-91408, 2016.

[26] F. Huang, Q. Xing, T. Liang et al., "2-(1-Aryliminoethyl)-9-arylimino-5,6,7,8-tetrahydrocycloheptapyridyl iro$\mathrm{n}$ (II) dichloride: synthesis, characterization, and the highly active and tunable active species in ethylene polymerization," Dalton Transactions, vol. 43, no. 44, pp. 16818-16829, 2014. 
[27] Y. Zhang, H. Suo, F. Huang, T. Liang, X. Hu, and W.-H. Sun, "Thermo-stable 2-(arylimino)benzylidene-9-arylimino-5,6,7,8-tetrahydrocyclohepta[b]pyridyliron (II) precatalysts toward ethylene polymerization and highly linear polyethylenes," Journal of Polymer Science Part A: Polymer Chemistry, vol. 55, no. 5, pp. 830-842, 2017.

[28] F. Huang, W. Zhang, E. Yue, T. Liang, X. Hu, and W.-H. Sun, "Controlling the molecular weights of polyethylene waxes using the highly active precatalysts of 2-(1-aryliminoethyl)9-arylimino-5,6,7,8-tetrahydrocycloheptapyridylcobalt chlorides: synthesis, characterization, and catalytic behavior," Dalton Transactions, vol. 45, no. 2, pp. 657-666, 2016.

[29] F. Huang, W. Zhang, Y. Sun, X. Hu, G. A. Solan, and W. H. Sun, "Thermally stable and highly active cobalt precatalysts for vinyl-polyethylenes with narrow polydispersities: integrating fused-ring and imino-carbon protection into ligand design," New Journal of Chemistry, vol. 40, no. 9, pp. 80128023, 2016.

[30] J. Guo, Z. Wang, W. Zhang et al., "Highly linear polyethylenes achieved using thermo-stable and efficient cobalt precatalysts bearing carbocyclic-fused NNN-pincer ligand," Molecules, vol. 24 , no. 6 , p. $1176,2019$.

[31] V. K. Appukuttan, Y. Liu, B. C. Son, C.-S. Ha, H. Suh, and I. Kim, "Iron and cobalt complexes of 2,3,7,8-tetrahydroacridine-4,-5(1H,6H)-diimine sterically modulated by substituted aryl rings for the selective oligomerization to polymerization of ethylene," Organometallics, vol. 30, no. 8, pp. 2285-2294, 2011.

[32] S. du, X. Wang, W. Zhang, Z. Flisak, Y. Sun, and W. H. Sun, “A practical ethylene polymerization for vinyl-polyethylenes: synthesis, characterization and catalytic behavior of $\alpha, \alpha^{\prime}$-bisimino-2,3:5,6-bis(pentamethylene)pyridyliron chlorides," Polymer Chemistry, vol. 7, no. 25, pp. 4188-4197, 2016.

[33] S. Du, W. Zhang, E. Yue, F. Huang, T. Liang, and W.-H. Sun, " $\alpha, \alpha$ '-Bis(arylimino)-2,3:5,6-bis(pentamethylene)pyridylcobalt chlorides: synthesis, characterization, and ethylene polymerization behavior," European Journal of Inorganic Chemistry, vol. 2016, no. 11, pp. 1748-1755, 2016.

[34] H. Suo, I. I. Oleynik, C. Bariashir et al., "Strictly linear polyethylene using Co-catalysts chelated by fused bis(arylimino)pyridines: probing ortho-cycloalkyl ring-size effects on molecular weight," Polymer, vol. 149, pp. 45-54, 2018.

[35] C. Bariashir, Z. Wang, H. Suo et al., "Narrow dispersed linear polyethylene using cobalt catalysts bearing cycloheptyl-fused bis(imino)pyridines; probing the effects of ortho-benzhydryl substitution," European Polymer Journal, vol. 110, pp. 240251, 2019.

[36] Z. Wang, R. Zhang, W. Zhang et al., "Enhancing thermostability of iron ethylene polymerization catalysts through $N, N, N$ chelation of doubly fused $\alpha, \alpha^{\prime}$-bis(arylimino)-2,3:5,6-bis(hexamethylene) pyridines," Catalysis Science \& Technology, vol. 9, no. 8, pp. 1933-1943, 2019.

[37] Z. Wang, G. A. Solan, Q. Mahmood et al., "Bis(imino)pyridines incorporating doubly fused eight-membered rings as conformationally flexible supports for cobalt ethylene polymerization catalysts," Organometallics, vol. 37, no. 3, pp. 380-389, 2018.

[38] Z. Wang, Y. Ma, J. Guo et al., "Bis(imino)pyridines fused with 6- and 7-membered carbocylic rings as $N, N, N$-scaffolds for cobalt ethylene polymerization catalysts," Dalton Transactions, vol. 48, no. 8, pp. 2582-2591, 2019.
[39] C. Bariashir, Z. Wang, S. Du et al., "Cycloheptyl-fused NNO-ligands as electronically modifiable supports for $\mathrm{M}$ (II) ( $\mathrm{M}=\mathrm{Co}, \mathrm{Fe}$ ) chloride precatalysts; probing performance in ethylene oligo-/polymerization," Journal of Polymer Science Part A: Polymer Chemistry, vol. 55, no. 24, pp. 3980-3989, 2017.

[40] A. S. Abu-Surrah, K. Lappalainen, U. Piironen, P. Lehmus, T. Repo, and M. Leskelä, "New bis(imino)pyridine-iron(II)and cobalt(II)-based catalysts: synthesis, characterization and activity towards polymerization of ethylene," Journal of Organometallic Chemistry, vol. 648, no. 1-2, pp. 55-61, 2002.

[41] W.-H. Sun, X. Tang, T. Gao, B. Wu, W. Zhang, and H. Ma, "Synthesis, characterization, and ethylene oligomerization and polymerization of ferrous and cobaltous 2-(ethylcarboxylato)-6-iminopyridyl complexes," Organometallics, vol. 23, no. 21, pp. 5037-5047, 2004.

[42] T. Xiao, P. Hao, G. Kehr, X. Hao, G. Erker, and W.-H. Sun, "Dichlorocobalt(II) complexes ligated by bidentate 8-(benzoimidazol-2-yl)quinolines: synthesis, characterization, and catalytic behavior toward ethylene," Organometallics, vol. 30, no. 18, pp. 4847-4853, 2011.

[43] Q. Chen, W. Zhang, G. A. Solan, T. Liang, and W.-H. Sun, "Methylene-bridged bimetallic bis(imino)pyridine-cobaltous chlorides as precatalysts for vinyl-terminated polyethylene waxes," Dalton Transactions, vol. 47, no. 17, pp. 6124-6133, 2018.

[44] Q. Chen, W. Zhang, G. A. Solan et al., "CH(phenol)-bridged bis(imino)pyridines as compartmental supports for diiron precatalysts for ethylene polymerization: exploring cooperative effects on performance," Organometallics, vol. 37, no. 21, pp. 4002-4014, 2018.

[45] D. J. Jones, V. C. Gibson, S. M. Green, P. J. Maddox, A. J. P. White, and D. J. Williams, "Discovery and optimization of new chromium catalysts for ethylene oligomerization and polymerization aided by high-throughput screening," Journal of the American Chemical Society, vol. 127, no. 31, pp. 11037-11046, 2005.

[46] A. K. Tomov, V. C. Gibson, G. J. P. Britovsek et al., "Distinguishing chain growth mechanisms in metal-catalyzed olefin oligomerization and polymerization systems: $\mathrm{C}_{2} \mathrm{H}_{4} / \mathrm{C}_{2} \mathrm{D}_{4}$ co-oligomerization/ polymerization experiments using chromium, iron, and cobalt catalysts," Organometallics, vol. 28, no. 24, pp. 7033-7040, 2009.

[47] G. M. Sheldrick, "SHELXT-integrated space-group and crystal structure determination," Acta Crystallographica Section A Foundations and Advances, vol. 71, no. 1, pp. 3-8, 2015.

[48] G. M. Sheldrick, "Crystal structure refinement with SHELXL," Acta Crystallographica Section C Structural Chemistry, vol. 71, no. 1, pp. 3-8, 2015. 